\title{
Functional assessment of miR-1291 in colon cancer cells
}

\author{
JIAQI WANG ${ }^{1}$, YUHKI YOKOYAMA ${ }^{1}$, HARUKA HIROSE ${ }^{1}$, YUKI SHIMOMURA ${ }^{1}$, SAKI BONKOBARA ${ }^{1}$, \\ HIROAKI ITAKURA ${ }^{2}$, SHIHORI KOUDA ${ }^{1}$, YOSHIHIRO MORIMOTO ${ }^{2}$, KAZUMASA MINAMI ${ }^{3}$, \\ HIDEKAZU TAKAHASHI ${ }^{2}$, SATOSHI SHIBATA ${ }^{1}$, SHOGO KOBAYASHI ${ }^{2}$, MAMORU UEMURA ${ }^{2}$, \\ SUSUMU TANAKA $^{4}$, XIN WU $^{1}$, SHINJI TANAKA ${ }^{5,6}$, MASAKI MORI $^{7}$ and HIROFUMI YAMAMOTO ${ }^{1,2}$ \\ ${ }^{1}$ Department of Molecular Pathology, Division of Health Sciences, Osaka University; Departments of ${ }^{2}$ Surgery and \\ Gastroenterological Surgery, and ${ }^{3}$ Radiation Oncology, Graduate School of Medicine, Osaka University; \\ ${ }^{4}$ First Department of Oral and Maxillofacial Surgery, Graduate School of Dentistry, Osaka University, Suita, Osaka 565-0871; \\ Departments of ${ }^{5}$ Molecular Oncology and ${ }^{6}$ Hepato-Billiary-Pancreatic Surgery, Graduate School of Medicine, \\ Tokyo Medical and Dental University, Tokyo 113-8510; ${ }^{7}$ Tokai University, Graduate School of Medicine, \\ Isehara, Kanagawa 259-1193, Japan
}

Received May 7, 2021; Accepted December 6, 2021

DOI: 10.3892/ijo.2022.5303

\begin{abstract}
R-1291 exerts an anti-tumor effect in a subset of human carcinomas, including pancreatic cancer. However, its role in colorectal cancer (CRC) is largely unknown. In the present study, the expression and effect of miR-1291 in CRC cells was investigated. It was identified that miR-1291 significantly suppressed the proliferation, invasion, cell mobility and colony formation of CRC cells. Additionally, miR-1291 induced cell apoptosis. A luciferase reporter assay revealed that miR-1291 directly bound the 3'-untranslated region sequence of doublecortin-like kinase 1 (DCLK1). miR-1291 also suppressed DCLK1 mRNA and protein expression in HCT116 cells that expressed DCLK1. Furthermore, miR-1291 suppressed cancer stem cell markers BMI1 and CD133, and inhibited sphere formation. The inhibitory effects on sphere
\end{abstract}

Correspondence to: Dr Yuhki Yokoyama, Department of Molecular Pathology, Division of Health Sciences, Osaka University, Yamadaoka 1-7, Suita, Osaka 565-0871, Japan

E-mail: yyokoyama@sahs.med.osaka-u.ac.jp

Abbreviations: Antagomir-1291, Hsa-miR-1291 inhibitor S-Tud; BMI1, B cell-specific Moloney murine leukemia virus integration site 1; BrdU, Bromodeoxyuridine; CDK, cyclin dependent kinase; CSC, cancer stem cell; CRC, colorectal cancer; Del, deleted type; DCLK1, doublecortin-like kinase 1; EGFR, epidermal growth factor receptor; EMT, epithelial-to-mesenchymal transition; ER, endoplasmic reticulum; KRAS, kirsten rat sarcoma virus; miRNA, microRNA; miR-1291, mimic-hsa-miR-1291; miR-NC, negative control miR; MUC1, mucin 1; Mut, mutated type; ODC, ornithine decarboxylase; RT-qPCR, quantitative real-time PCR; sCA, super carbonate apatite; sh, short hairpin; siRNA, small interfering RNA; STR, short tandem repeat; TGF- $\beta$, transforming growth factor- $\beta$; 3'UTR, 3'-untranslated region

Key words: colorectal cancer, miR-1291,p21 ${ }^{\mathrm{CIP} / \mathrm{WAF} 1}, \mathrm{p} 27^{\mathrm{KIP} 1}, \mathrm{DCLK} 1$ formation, invasion and mobility in HCT116 cells were also explored and verified using DCLK1 siRNAs. Furthermore, miR-1291 induced CDK inhibitors p21 ${ }^{\mathrm{WAF} 1 / \mathrm{CIP} 1}$ and $\mathrm{p} 27^{\mathrm{KIP} 1}$ in three CRC cell lines, and the overexpression of DCLK1 in HCT116 cells led to a decrease of $\mathrm{p} 21^{\mathrm{WAF} 1 / \mathrm{CIP} 1}$ and $\mathrm{p} 27^{\mathrm{KIP} 1}$. Intravenous administration of miR-1291 loaded on the super carbonate apatite delivery system significantly inhibited tumor growth in the DLD-1 xenograft mouse model. Additionally, the resultant tumors exhibited significant upregulation of the $\mathrm{p} 21^{\mathrm{WAF} 1 / \mathrm{CIP} 1}$ and $\mathrm{p} 27^{\mathrm{KIP} 1}$ protein with treatment of miR-1291. Taken together, the results indicated that miR-1291 served an anti-tumor effect by modulating multiple functions, including cancer stemness and cell cycle regulation. The current data suggested that miR-1291 may be a promising nucleic acid medicine against CRC.

\section{Introduction}

Colorectal cancer (CRC) was the third most widespread cancer and the second most deadly cancer in 2018, worldwide. There were 1,800,977 new cases of CRC and 861,663 related deaths in $2018(1,2)$. In the past few decades, improved treatment options have become available, including surgery, radiotherapy, chemotherapy and molecular-targeted therapy for advanced CRC $(3,4)$. However, the 5-year survival rate of $\mathrm{CRC}$ is $<65 \%$ due to cancer relapse (2).

MicroRNAs (miRNAs) are short (18-25 nucleotides) non-coding RNAs that mainly bind to the 3'-untranslated region (3'UTR) of target mRNAs, contributing to mRNA cleavage or translational suppression $(5,6)$. miRNAs play an important role in numerous biological processes, such as immune response (7), neurogenesis (8) and insulin secretion (9). In addition, miRNAs contribute to various processes in cancer, including tumor growth, apoptosis, invasion and survival of patients, which are closely related to oncogenesis and tumor progression $(10,11)$.

Previous studies have demonstrated that the pathological mechanisms underlying CRC depend on a variety of signaling 
pathways, including Wnt/ $\beta$-catenin, epidermal growth factor receptor (EGFR), transforming growth factor- $\beta$ (TGF- $\beta$ ), tumor protein p53 and epithelial-to-mesenchymal transition (EMT) (12-16). Furthermore, miRNAs have been determined to play a pivotal role in regulating these pathways. For example, miR-4689 exerts an anti-tumor effect on mutant kirsten rat sarcoma virus (KRAS) in CRC by inhibiting the EGFR and AKT pathway (17). MIRTX, a byproduct of miR-29b-1-5p suppresses the $\mathrm{NF}-\kappa \mathrm{B}$ signaling pathway in KRAS-mutated CRC cells by directly binding to $\mathrm{CXC}$ chemokine receptor 2 and phosphatidylinositol 3-kinase regulatory subunit alpha mRNA (18). In addition, miR-34a can inhibit cell proliferation and increase the expression of p21 $1^{\mathrm{WAF} 1 / \mathrm{CIP} 1}$ in HCT116 and RKO CRC cells (19). It has been recently reported that miR-4711-5p regulates cancer stemness and the cell cycle in CRC cells by targeting Kruppel-like factor 5, mouse double minute 2 homolog and transcription factor Dp-1 (20).

Cancer stem cells (CSCs) have distinct capability for self-renewal and multi-potential differentiation (21). CSCs confer resistance to anticancer drugs and radiotherapy, and thus cause distant metastases and recurrence (22-24). Several CSC markers for CRC have been identified, including CD133, B cell-specific Moloney murine leukemia virus integration site 1 (BMI1) and leucine rich repeat containing $\mathrm{G}$ protein-coupled receptor $5(23,25,26)$. Previously, doublecortin-like kinase 1 (DCLK1) was demonstrated to be a CSC marker in CRC $(27,28)$. DCLK1 belongs to the protein kinase superfamily and is overexpressed in several human malignancies, including colorectal, pancreas and kidney cancer (29-31). Our preliminary data also demonstrated that miR-1291 exhibited a potent growth inhibitory effect on pancreatic cancer stem-like cells in which the ornithine decarboxylase (ODC) degron was transduced (32-34).

It has been reported that miR-1291 sensitizes cells to doxorubicin by suppressing multidrug resistance-associated protein 1 (35). Additionally, miR-1291 is considered to be a candidate biomarker for the diagnosis of acute myocardial infarction (36) and Bullous Pemphigoid (37), and is also a marker for the prediction of severe symptoms in SARS-CoV-2 infection (38). In relation to human cancers, miR-1291 has been reportedly upregulated in liver cirrhosis and hepatocellular carcinoma (39). In addition, miR-1291 is a biologically relevant regulator of glypican-3 expression in hepatoma cells and acts by silencing the endoplasmic reticulum (ER) stress sensor, inositol-requiring transmembrane kinase/endoribonuclease $1 \alpha$ (40). Several studies have demonstrated that miR-1291 inhibits cell proliferation and tumorigenesis, and sensitizes pancreatic cancer cells to chemotherapy (41-43). Furthermore miR-1291 is reportedly downregulated in kidney, esophagus and prostate carcinoma, serving anti-tumor effects (44-46). The target molecules for miR-1291 include solute career family 2 member $1 /$ glucose transporter 1 in renal cancer cells, mucin 1 (MUC1) in human esophagus cancer cells $(44,45)$ and forkhead box protein A2-anterior gradient 2 pathway in PANC-1 pancreatic cancer cells (43). Furthermore, miR-1291 has been demonstrated to inhibit cell growth and tumorigenesis in prostate cancer by binding to Mediator Complex Subunit 1 (46).

Detailed functional assessments of miR-1291 have not yet been conducted in CRC. However, Salehi et al (47) reported that miR-1291 levels were slightly increased in liver metastasis compared with primary CRC by using the NCBI Gene Expression Omnibus (GEO) database (47). Therefore, the aim of the present study was to clarify the anti-tumor effect of miR-1291 in CRC cells, partially including DCLK1 regulation.

\section{Materials and methods}

Cell lines and cell culture. Human CRC cell lines (CACO-2, COLO205, DLD-1, HCT116, LoVo, RKO and SW480), the human pancreatic cancer cell line Panc-1, and non-tumor cell lines (293, CCD-18Co and MRC5) were purchased from the American Type Culture Collection. The HT29 cell line (cat. no. KBN0398_01) was obtained from Japanese Collection of Research Bioresources Cell Bank. Short tandem repeat (STR) profiling for authentication indicated that the HT29 cell line was the same as the one registered with the American Type Culture Collection (HTB-38 HT-29: human adenocarcinoma; Colorectal). KM12SM (48) was a gift from Professor Toshinari Minamoto (Cancer Research Institute, Kanazawa University, Kanazawa, Japan). These cell lines were authenticated by morphological inspection, STR profiling and mycoplasma testing. Cells were cultured either in RPMI 1640 medium or in DMEM (each, Nissui Pharmaceutical Co., Ltd.) supplemented with 10\% FBS (Biowest SAS), $100 \mathrm{U} / \mathrm{ml}$ penicillin and $100 \mu \mathrm{g} / \mathrm{ml}$ streptomycin (Nacalai Tesque, Inc.). Cells were cultured in a humidified incubator at $37^{\circ} \mathrm{C}$ in an atmosphere containing $5 \% \mathrm{CO}_{2}$.

Retroviral transduction of the degron reporter into pancreatic cancer Panc-1 cells. The degron sequence of ornithine decarboxylase (ODC) is recognized directly by proteasomes, which leads to the destruction of the involved protein. The retroviral expression vector pQCXIN-ZsGreen-cODC, containing green fluorescence ZsGreen-labeled degron ODC (Gdeg) was kindly provided by Dr Frank Pajonk (Jonsson Comprehensive Cancer Center, UCLA, CA, USA). The plasmid was transfected into Platinum retroviral packaging cells using Lipofectamine ${ }^{\circledR} 2000$ (Thermo Fisher Scientific, Inc.). The plasmid and Lipofectamine ${ }^{\circledR} 2000$ were diluted with Opti-MEM I reduced serum medium (Thermo Fisher Scientific, Inc.) for $5 \mathrm{~min}$ at room temperature, separately. The diluted Lipofectamine ${ }^{\circledR} 2000$ was subsequently mixed with the diluted plasmid and incubated for $15 \mathrm{~min}$ at room temperature. The mixture was then added to cells immediately at room temperature, after which the cells were incubated at $37^{\circ} \mathrm{C}$. And the retrovirus collected from the supernatant was used for Panc-1 cell infection as previously described (32-34). Stable transfectants were selected with G418 solution (Sigma-Aldrich; Merck KGaA) and maintained in $0.1 \mathrm{mg} / \mathrm{ml} \mathrm{G} 418$ solution.

Clinical tissue samples. When the tumor diameter $>3 \mathrm{~cm}$, paired clinical tissue specimens (normal mucosa and CRC tissue) were randomly collected from 20 patients (10 males and 10 females; age range, 18-87 years) who had surgery for colorectal cancer at Osaka University Hospital (Osaka, Japan) between October 2016 and April 2017. All tissue specimens were stored at $-80^{\circ} \mathrm{C}$ until RNA extraction. This study was performed in accordance with the Declaration of Helsinki. All patients provided written informed consent, in 
accordance with the guidelines approved (approval no. 08226) by the Institutional Research Board of the institute. The present study was conducted under the supervision of and approved by the Ethics Board of Osaka University Hospital.

miRNA, antagomir, siRNA and plasmid transfection. Mimic-hsa-miR-1291 (miR-1291) sense (5'-UGGCCCUGA CUGAAGACCAGCAGU-3') and antisense (5'-ACUGCU GGUCUUCAGUCAGGGCCA-3') sequences, along with the negative control $\mathrm{miR}$ (miR-NC) sense (5'-AUCCGCGCG AUAGUACGUA-3') and antisense (5'-UACGUACUAUCG CGCGGAU-3') sequences were designed and synthesized by Ajinomoto Bio-Pharma. Hsa-miR-1291 inhibitor S-Tud (antagomir-1291) sense [5'-GACGGCGCUAGGAUCAUC AACACUGCUGGUCUUCAGUCAGGGCCACAAGUA UUCUGGU-3'] and antisense [5'-ACCAGAAUACAACAC UGCUGGUCUUCAGUCAGGGCCACAAGAUGAUCC UAGCGCCGUC-3'] were 2-OMethyl modified, and were also designed and synthesized by Ajinomoto Bio-Pharma. Three small interfering RNAs (siRNAs) targeting DCLK1 were obtained from Thermo Fisher Scientific, Inc. (Assay IDs: s17584, s17585 and s17586). Cells were transfected with miRNAs, antagomir, and siRNAs at final concentration of 30-50 $\mathrm{nM}$ and plasmids at concentration of $50 \mathrm{ng}$ per well (96-well plate) or $1 \mu \mathrm{g}$ per well (six-well plate) using Lipofectamine ${ }^{\circledR} 2000$ or Lipofectamine ${ }^{\circledR}$ RNAiMAX (both from Thermo Fisher Scientific, Inc.) The nucleotide (miRNAs, antagomir, siRNAs and plasmids) and transfection reagent (Lipofectamine ${ }^{\circledR} 2000$ or Lipofectamine ${ }^{\circledR}$ RNAiMAX) were diluted with serum free medium (RPMI-1640 or DMEM) for 5 min at room temperature, separately. The diluted transfection reagent was subsequently mixed with the diluted nucleotide and incubated for $15 \mathrm{~min}$ at room temperature. The mixture was then added to cells immediately at room temperature, after which the cells were incubated at $37^{\circ} \mathrm{C}$. The subsequent experiments were performed at 4 and $24 \mathrm{~h}$ after transfection for miRNA uptake into cells and from 24 to $72 \mathrm{~h}$ for various anti-tumor feature assessments.

RNA isolation. Total RNA was collected from each cell line using TRIzol ${ }^{\circledR}$ Reagent (Thermo Fisher Scientific, Inc.) followed by phenol-chloroform extraction and ethanol precipitation. Subsequently, miRNA was collected from tissue specimens and cultured cells using the miRNeasy kit (Qiagen $\mathrm{GmbH}$ ) according to the manufacturer's protocol. Total RNA concentration and purity were measured using a NanoDrop one spectrophotometer (Thermo Fisher Scientific, Inc.) at 260 and $280 \mathrm{~nm}\left(\mathrm{~A}_{260 / 280}\right)$ wavelengths.

Reverse transcription-quantitative $(R T-q) P C R$ analysis of $m R N A$. A High Capacity cDNA Reverse Transcription kit (Thermo Fisher Scientific, Inc.) was used to synthesize complementary DNA from $2.5 \mu \mathrm{g}$ of total RNA according to the manufacturer's protocol. qPCR for DCLK1, BMI1 and CD133 RNA was performed using oligonucleotide primers and the LightCycler 480 Real-Time PCR system (Roche Diagnostics). The amplification products were detected using the THUNDERBIRD SYBR qPCR Mix (Toyobo Life Science), and the level of target gene expression was calculated. The qPCR conditions were as follows: $95^{\circ} \mathrm{C}$ for
$30 \mathrm{sec}$; followed by 40 cycles of $95^{\circ} \mathrm{C}$ for $10 \mathrm{sec}, 60^{\circ} \mathrm{C}$ for $10 \mathrm{sec}$ and $72^{\circ} \mathrm{C}$ for $30 \mathrm{sec}$. The expression of the target gene was normalized to endogenous GAPDH expression. Relative expression was quantified by the $2^{-\Delta \Delta C q}$ method (49). The PCR primers are listed in Table SI.

RT-qPCR analysis of miRNA. The TaqMan MicroRNA Reverse Transcription kit (Thermo Fisher Scientific, Inc.) was used to synthesize the complementary DNA from $25 \mathrm{ng}$ of total RNA according to the manufacturer's protocol. qPCR of miRNA was then performed using TaqMan Universal PCR Master Mix, No AmpErase UNG (Thermo Fisher Scientific, Inc.) with a 7900 HT Sequence Detection System (Thermo Fisher Scientific, Inc.). RNU6B was used as the endogenous control. The primers for miR-1291 and RNU6B were designed by Thermo Fisher Scientific, Inc. (miR-1291, Assay ID: 002838; RNU6B, Assay ID: 001093; cat. no. 4427975). The qPCR conditions were as follows: $95^{\circ} \mathrm{C}$ for $10 \mathrm{~min}$; followed by 45 cycles of $95^{\circ} \mathrm{C}$ for $15 \mathrm{sec}$, and $60^{\circ} \mathrm{C}$ for $1 \mathrm{~min}$ and $72^{\circ} \mathrm{C}$ for $1 \mathrm{sec}$; cooling to $40^{\circ} \mathrm{C}$ for $30 \mathrm{sec}$. Relative expression was quantified with the $2^{-\Delta \Delta \mathrm{Cq}}$ method.

Cell viability assay. Cells were seeded in 96-well plates at a density of 4,000-8,000 cells per well and were transfected with miR-NC or miR-1291 or antagomir-1291 or DCLK1-siRNA at a final concentration of $30 \mathrm{nM}$ as aforementioned, the second day after seeding. A total of 24,48 and $72 \mathrm{~h}$ after transfection, $10 \mu \mathrm{l}$ Cell Counting Kit-8 (Dojindo Molecular Technologies, Inc.) solution was added to each well, after which the 96-well plates were kept in dark for $2 \mathrm{~h}$ at $37^{\circ} \mathrm{C}$. The absorbance was then detected using a Multiskan Go plate reader (Thermo Fisher Scientific, Inc.). The differences in absorption at 630 and $450 \mathrm{~nm}$ wavelengths were then subtracted and used to determine cell viability.

Matrigel invasion assay. Corning BioCoat Matrigel Invasion Chambers (pore size: $8.0 \mu \mathrm{m}$; Corning, Inc.; cat. no. 354480) were used. The upper chamber, which was pre-coated with Matrigel, was rehydrated with culture medium (RPMI-1640 or DMEM) for $2 \mathrm{~h}$ at $37^{\circ} \mathrm{C}$ in $5 \% \mathrm{CO}_{2}$ before seeding the cells. The medium (RPMI-1640 or DMEM) was then removed, and DLD-1, HT29 and HCT116 cells were seeded into the upper chambers at a density of $1-2 \times 10^{5}$ cells per chamber with medium (RPMI-1640 or DMEM) containing $0.1 \%$ bovine serum albumin. Medium (RPMI-1640 or DMEM) containing $10 \%$ FBS were put in the lower wells. The cells were transfected with the miRNAs or antagomir or DCLK1-siRNA at a final concentration of $50 \mathrm{nM}$ and incubated at $37^{\circ} \mathrm{C}$ after transfection. After incubation for 48,72 and $96 \mathrm{~h}$, cells passing through the Matrigel were fixed with $10 \%$ formalin for $1 \mathrm{~h}$ at room temperature and then stained with hematoxylin for $1 \mathrm{~h}$ at room temperature. To count cells passing through the Matrigel, images were captured using a bright field light microscope (CKX53; Olympus Corporation) with Visualix camera (Visualix, Corporation) at a magnification of $\mathrm{x} 200$.

Gap closure assay. Ibidi culture inserts (8.4 width x8.4 length x5 mm height; Ibidi $\mathrm{GmbH}$ ) with two $70 \mu \mathrm{l}$ wells were put on the 24-well plates before cell seeding. DLD-1, HT29 and HCT116 cell suspensions $(70 \mu \mathrm{l})$ were then added into each 
$70 \mu 1$ well at a density of $2 \times 10^{5}, 2.5 \times 10^{5}$ and $8 \times 10^{5}$ cells per $\mathrm{ml}$, respectively. The inserts were removed after $24 \mathrm{~h}$ to create gap with an area of $6 \times 10^{5}$ pixel $^{2}$. After that, the miRNAs or antagomir or DCLK1-siRNA were transfected at a final concentration of $30 \mathrm{nM}$. To enhance gap closure, cells were cultured in the medium (RPMI-1640 or DMEM) supplemented with $10 \%$ FBS as previously described (50,51). At 24 and $48 \mathrm{~h}$ after transfection, images were captured by a bright field light microscope (CKX53; Olympus Corporation) with Visualix camera (Visualix, Corporation) at a magnification of x100. The areas of the gaps were measured using ImageJ $1.52 \mathrm{v}$ software (National Institutes of Health).

Colony formation assay. Cells were seeded in a six-well plate at a density of $1 \times 10^{5}$ cells per well, incubated at $37^{\circ} \mathrm{C}$ overnight and transfected with miR-NC or miR-1291 at a final concentration of $30 \mathrm{nM}$ for $8 \mathrm{~h}$. Samples were then reseeded in six-well plates at a density of 500 cells per well. A colony was considered to consist of $\geq 50$ cells. Cells were incubated for 10 days at $37^{\circ} \mathrm{C}$ after transfection, after which cells were fixed with $100 \%$ methanol for $30 \mathrm{~min}$ at room temperature, and stained by $0.5 \%$ crystal violet for $10 \mathrm{~min}$ at room temperature for counting. The images of each well were scanned using an Epson scanner GT-X970 (Seiko Epson Corporation), and the colonies were counted using ImageJ 1.52v software (National Institutes of Health).

Cell cycle assay. DLD-1, HT29 and HCT116 cells were seeded to six-well plates at a density of $3 \times 10^{5}, 4 \times 10^{5}$ and $3.5 \times 10^{5}$ cells per well, respectively. Cells were starved in serum-free medium (RPMI-1640 or DMEM) for $48 \mathrm{~h}$. A total of $24 \mathrm{~h}$ before the end of starvation, miR-NC or miR-1291 was transfected at a final concentration of $30 \mathrm{nM}$. Cells were collected at the indicated times $(0,12,24$ and $48 \mathrm{~h})$ and fixed in $70 \%$ ethanol for $30 \mathrm{~min}$ at $4^{\circ} \mathrm{C}$. After fixation, cells were washed twice with PBS and incubated with RNase (Sigma Aldrich; Merck KGaA) for $20 \mathrm{~min}$ at $37^{\circ} \mathrm{C}$. Cells were treated with propidium iodide (PI; Dojindo Molecular Technologies, Inc.) for $20 \mathrm{~min}$ on ice and analyzed by flow cytometry (Spectral Analyzer SA3800; Sony Biotechnology, Inc.) with SA3800 2.0 software (Sony Biotechnology, Inc.).

Bromodeoxyuridine (BrdU) Proliferation assay. Cell proliferation assays were performed using CysLex Cellular BrdU ELISA kit Ver.2. (Medical \& Biological Laboratories Co., Ltd.). Cells were cultured with BrdU labeling reagent at $10 \mu \mathrm{M}$ for $2 \mathrm{~h}$ at $37^{\circ} \mathrm{C}$, then incubated with $50 \mu 1$ per well of anti-BrdU monoclonal antibody (provided in the kit) for $1 \mathrm{~h}$ at room temperature, followed by $50 \mu \mathrm{l}$ per well of secondary antibody reaction with HRP-conjugated anti-mouse $\mathrm{IgG}$ (provided in the kit), for $1 \mathrm{~h}$ at room temperature. After the addition of the substrate reagent (provided in the kit), the absorbance in each well was measured using a Multiskan Go microplate spectrophotometer (Thermo Fisher Scientific, Inc.) at dual wavelengths of $450 / 540 \mathrm{~nm}$.

Annexin V apoptosis assay. Apoptotic cells were assessed using an Alexa Fluor 488. Annexin V/Dead Cell Apoptosis kit (Thermo Fisher Scientific, Inc.). A total of $2 \times 10^{5}$ cells were diluted with $100 \mu 1 \mathrm{1X}$ annexin-binding buffer, after which
$5 \mu \mathrm{l}$ Alexa Flour 488 Annexin V and $1 \mu 1100 \mu \mathrm{g} / \mathrm{ml}$ PI was added. Samples were subsequently incubated for $15 \mathrm{~min}$ at room temperature. A total of $400 \mu 11 \mathrm{X}$ annexin-binding buffer was added to each cell suspension and apoptotic cells were counted by flow cytometry using Spectral Analyzer SA3800 (Sony Biotechnology, Inc.) with SA3800 2.0 software (Sony Biotechnology, Inc.).

Western blot analysis. Cells were seeded in six-well plates at a density of $1 \times 10^{5}-2 \times 10^{5}$ per well and transfected with miR-NC, miR-1291 or DCLK1-siRNA at a final concentration of 30-50 nM. After 48 and $72 \mathrm{~h}$, cells were rinsed twice with PBS and lysed by RIPA buffer $(0.05 \mathrm{M}$ Tris-HCl, $\mathrm{pH}$ 7.6, $0.15 \mathrm{M}$ $\mathrm{NaCl}, 1 \%$ Nonidet $\mathrm{P} 40,0.5 \%$ sodium deoxycholate, $0.1 \%$ SDS) with $1 \%$ proteinase inhibitor cocktail (Nacalai Tesque, Inc.). The protein samples (30 $\mu \mathrm{g} / \mathrm{lane})$ were electrophoresed by SDS-PAGE using 10, 13 or $15 \%$ acrylamide gel and transferred to PVDF transfer membranes (Bio-Rad Laboratories, Inc.). The membranes were blocked with 5\% non-fat dry milk (Cell Signaling Technology, Inc.) in TBS with Tween-20 (TBS-T; $50 \mathrm{mM}$ Tris, $158 \mathrm{mM} \mathrm{NaCl}, 2.7 \mathrm{mM} \mathrm{KCl}, \mathrm{pH} 7.5$, $0.1 \%$ Tween-20) for $1 \mathrm{~h}$ at room temperature and incubated with the following primary antibodies overnight at $4^{\circ} \mathrm{C}$ : Anti-ACTB (1:4,000; Rabbit mAb, cat. no. 4970; Cell Signaling Technology, Inc.), and anti-DCLK1 (1:2,000; cat. no. ab31704; Abcam) anti-p21 ${ }^{\text {WAFI/CIP1 }}$ (1:1,000; cat. no. ab80633; Abcam), anti-p2 $7^{\mathrm{KIP} 1}(1: 1,000$; sc-528, Santa Cruz Biotechnology, Inc.), anti-CD133 (1:1,000; ab216323; Abcam), anti-CDC25A (1:1,000; cat. no. 3652; Cell Signaling Technology, Inc.), anti-CDC25B (1:1,000; cat. no. 9525; Cell Signaling Technology, Inc.), anti-CDC25C Rabbit mAb (1:1,000; cat. no. 4688; Cell Signaling Technology, Inc.), anti-CDK4 (1:1,000; cat. no. MAB8879; MilliporeSigma), anti-CDK6 (1:1,000; cat. no. SAB4300596; Sigma-Aldrich; Merck KGaA), anti-Cyclin D1 (1:1,000; cat. no. 2922; Cell Signaling Technology,Inc.), anti-Cyclin E1 (1:1,000; cat. no. sc-247; Santa Cruz Biotechnology, Inc.), anti-retinoblastoma (Rb; 1:1,000; cat. no. ab24; Abcam), anti-cdc2 (1:1,000; cat. no. 77055; Cell Signaling Technology, Inc.) and anti-phosphorylated (p)-cdc2 [(Tyr15); 1:1,000; cat. no. 9111; Cell Signaling Technology, Inc.)]. Subsequently, the membranes were incubated with secondary antibodies, including HRP anti-mouse IgG (1:3,000; cat. no. NA931; GE Health Care Life Sciences) or anti-rabbit IgG antibodies (1:3,000; cat. no. NA934; GE Healthcare Life Sciences) for $1 \mathrm{~h}$ at room temperature. The bands were visualized by the ECL Detection System (GE Healthcare Life Sciences) and analyzed using ImageJ $1.52 \mathrm{v}$ software (National Institutes of Health).

pmirGLO plasmid vector construction. The 3'UTR of DCLK1 mRNA was amplified by PCR using the following primer sequences (amplified product size, $211 \mathrm{bp}$ ): forward, 5'-GCTCGCTAGCCTCGAGCTAGTGTACTGAGCCTGCG G-3' and reverse, 5'-ATGCCTGCAGGTCGACTGACT GGTCACATTCCACTG-3'. The amplified products were subcloned and ligated into the multicloning site between SalI and XhoI in the pmirGLO Dual-Luciferase miRNA Target Expression Vector (Promega Corporation) using the In-Fusion HD Cloning kit (Clontech Laboratories, Inc.) The vectors with mismatched 3'UTR sequences were constructed 
using the QuikChange Site Directed Mutagenesis kit (Agilent Technologies, Inc.) according to the manufacturer's protocol. The PCR primers for mutated type and deleted type plasmids are listed in Table SI. The entire sequence (insert and vector) was confirmed by Sanger sequencing (outsourced to Genome Information Research Center, Osaka University, Suita, Osaka).

Luciferase reporter assay. Cells were seeded in 96-well plates at a density of $1 \times 10^{4}$ cells per well and transfected with $50 \mathrm{ng}$ of DCLK1 wild type, 2-nucleotide mutated type (Mut) or 3-nucleotide deleted type (Del) 3'UTR containing pmirGLO Dual-Luciferase miRNA Target Expression Vector (aforementioned) using Lipofectamine ${ }^{\circledR} 2000$ (Thermo Fisher Scientific, Inc.). Additionally, $50 \mathrm{nM}$ of either miR-NC sense (5'-AUCCGCGCGAUAGUACGUA-3') and antisense (5'-UAC GUACUAUCGCGCGGAU-3') sequences or miR-1291 sense (5'-UGGCCCUGACUGAAGACCAGCAGU-3') and antisense (5'-ACUGCUGGUCUUCAGUCAGGGCCA-3') sequences, which were designed and synthesized by Ajinomoto Bio-Pharma, were transfected using Lipofectamine ${ }^{\circledR}$ RNAiMAX (Thermo Fisher Scientific, Inc.). After $24 \mathrm{~h}$ of transfection, cells were assayed for both firefly and Renilla luciferase using the Dual-Luciferase Reporter Assay System (Promega Corporation).

Transient overexpression of DCLK1 in HCT116. Total complementary DNA (cDNA) was synthesized using the High Capacity cDNA Reverse Transcription kit (Thermo Fisher Scientific, Inc.) from total RNA, which was obtained from the SW480 CRC cell line as aforementioned, and performed in accordance with the manufacturers protocol. The coding sequence of DCLK1 (NCBI Reference Sequence: NM_001195416.2) was amplified from total cDNA via PCR using the KOD FX Neo (Toyobo Life Science). The PCR conditions were as follows: $94^{\circ} \mathrm{C}$ for $2 \mathrm{~min}$; followed by 40 cycles of $60^{\circ} \mathrm{C}$ for $10 \mathrm{sec}, 62^{\circ} \mathrm{C}$ for $30 \mathrm{sec}$ and $68^{\circ} \mathrm{C}$ for $60 \mathrm{sec}$. The concentration and purity of DCLK1 cDNA were measured using a NanoDrop one spectrophotometer (Thermo Fisher Scientific, Inc.) at 260 and $280 \mathrm{~nm}$ (A260/280) wavelengths. The primer sequences (amplified product size, 1302 bp) were as follows: BamHI_DCLK1_forward, 5'-TAC CGAGCTCGGATCCATGTTAGAACTCATAGAAGTTA-3' and reverse, 5'-GATATCTGCAGAATTCTTAAAAGGGCG AGTTAGGG-3'. The amplified product was subcloned and ligated into the multicloning site between BamHI and EcoRI in the pcDNA3.1 plasmid (Thermo Fisher Scientific, Inc.) using the In-Fusion HD Cloning kit (Clontech Laboratories, Inc.). The DCLK1-inserted vector or empty vector was transfected to HCT116 cells by Lipofectamine ${ }^{\circledR} 2000$.

ShDCLK1 HCT116 clones. Sh (short hairpin)-DCLK1 HCT116 clones were generated as previously described (29). ShDCLK1 \#1 (Clone ID: TRCN0000002145) targeted the sequence 5'-GAACTGTATCTTGTCATGGAA-3'. ShDCLK1 \#2 (Clone ID: TRCN0000002146) targets the sequence 5'-CAGGTATCTTTGTAGCGGTTT-3'.

Sphere formation assay. HCT116 cells were seeded in six-well plates at a density of $1 \times 10^{5}$ cells per well, incubated at $37^{\circ} \mathrm{C}$ overnight, and transfected with miR-NC or miR-1291 or DCLK1-siRNA at a final concentration of $50 \mathrm{nM}$. After $24 \mathrm{~h}$ of transfection, single cells were reseeded in 96-Well Clear Ultra Low Attachment Microplates (Corning, Inc.) at a density of 1,000 cells per well. The cells were cultured in DMEM/ F-12 serum-free medium (Thermo Fisher Scientific, Inc.) supplemented with $20 \mathrm{ng} / \mathrm{ml}$ epithelial growth factor, $10 \mathrm{ng} / \mathrm{ml}$ basic fibroblast growth factor-2 (PeproTech, Inc.), $100 \mathrm{U} / \mathrm{ml}$ penicillin and $100 \mu \mathrm{g} / \mathrm{ml}$ streptomycin. Cells were cultured in a humidified incubator at $37^{\circ} \mathrm{C}$ and $5 \% \mathrm{CO}_{2}$. Images were captured by a bright field light microscope (CKX53; Olympus Corporation) with Visualix camera (Visualix, Corporation). The number of spheres was counted manually on days 4 or 7 after reseeding.

Flow cytometric analysis. HCT116 cells were seeded in six-well plates at a density of $1 \times 10^{5}$ cells per well, incubated at $37^{\circ} \mathrm{C}$ overnight and transfected with miR-NC or miR-1291 at a final concentration of $50 \mathrm{nM}$. For CD133 marker expression, after $48 \mathrm{~h}$ of transfection, cells were resuspended and one million cells were incubated with antibodies against human CD133 (1:50; APC-conjugated; cat. no. 130-113-106; Miltenyi Biotec $\mathrm{GmbH}$ ) on ice for 20 min in the dark. Samples were then washed twice with PBS containing 2\% FBS. For CD166 marker expression, after 72 and $96 \mathrm{~h}$ of transfection, the cells were resuspended and one million cells were incubated with PE Mouse Anti-Human CD166 antibody (1:6.7; cat. no. 559263; BD Biosciences on ice for $20 \mathrm{~min}$ in the dark. Samples were then washed twice with PBS containing 2\% FBS. The Spectral Analyzer SA3800 (Sony Biotechnology, Inc.) with SA3800 2.0 software (Sony Biotechnology, Inc.) was used for flow cytometric analyses. Dead cells were excluded by utilizing forward and side scatter.

In vivo experiments. DLD-1 cells were mixed with Matrigel (Corning, Inc.) and RPMI-1640 at a 1:1 ratio (vol:vol). Subsequently, $\sim 2 \times 10^{6}$ cells in $100 \mu 1$ RPMI-1640/Matrigel solution were injected subcutaneously into both sides of the lower back regions of 17 4-week-old female nude mice (CLEA Japan, Inc.). The mice were divided randomly into a parent group $(\mathrm{n}=5)$, a miR-NC group $(\mathrm{n}=6)$ and a miR-1291 group $(\mathrm{n}=6)$ for the evaluation of anti-tumor growth effects and safety. After tumor volumes reached $80 \mathrm{~mm}^{3}$, miRNA was formulated with super carbonate apatite (sCA), which was intravenously administered as the vehicle via the tail vein at a dose of $40 \mu \mathrm{g}$ per injection as previously described $(17,18,20,52-55)$. Mice were treated eight times with formulated miR-NC or miR-1291 over 2 weeks. The tumors were resected on day 14 . Tumor volumes were determined as previously described $(17,18)$. The animal facility was specific pathogen free and was kept at $20-24^{\circ} \mathrm{C}$ with 40-60\% humidity. The dark/light cycle was $12 / 12 \mathrm{~h}$. All animals could access food and water ad libitum. All animal experiments were performed in accordance with currently prescribed guidelines and the Animal (Scientific Procedures) 1986 Act. Regarding the tumor burden, a marked increase in tumor size ( $\geq 10 \%$ body weight) was applied as one a humane endpoints according to Guidelines for Proper Conduct of Animal Experiments by Science Council of Japan in 2006 (56). The present study was approved (approval no. 13377-5) by the Ethics Board of Osaka University (Osaka, Japan). Physical 
methods of euthanasia were applied. Thus, mice were anesthetized by isoflurane (4-5\%), followed by immediate incision in the abdomen, and successive cut of diaphragm and the post caval vein. After that, the death of mice was verified by assessing the observation of respiratory arrest, cessation of heart beat (lack of activity for $\geq 5 \mathrm{~min}$ ) (56) and pupillary response to light (57). The weight of the animals ranged from 15.6 to $20.3 \mathrm{~g} /$ mouse on day 0 , and at the time of sacrifice (on day 14) ranged from 16.2 to $21.8 \mathrm{~g} /$ mouse.

In silico analysis. TargetScan human version 7.2 (http://www. targetscan.org/vert_72/), miRwalk (http://mirwalk.umm. uni-heidelberg.de/), miRabel (http://bioinfo.univ-rouen. $\mathrm{fr} / \mathrm{mirabel} / \mathrm{view} / \mathrm{result}$.php? page $=\mathrm{mir}$ ), and $\mathrm{miRmap}$ (https://mirmap.ezlab.org/app/) were utilized to search and crosscheck the target candidates of miR-1291. The tissue atlas database (https://ccb-web.cs.uni-saarland. de/tissueatlas/patterns) was used to examine basal expression of miRNAs in normal tissues.

Statistical analysis. Data are presented as the mean \pm SEM. Statistical analyses were performed using GraphPad Prism 5 (GraphPad Software, Inc.) and Microsoft Excel (Microsoft Corporation). Statistical differences between the miR-NC and miR-1291 groups were analyzed by Student's t-test (two-tailed, unpaired). The expression levels of miRNAs in normal and cancer colorectal tissues were analyzed using the Wilcoxon signed-rank test (two-tailed, paired). In Table SII, Student's t-test (two-tailed, unpaired) was used for analyzing the statistical differences of age and tumor size, and Fisher's exact test was used for other clinicopathological characteristics of tumors. $\mathrm{P}<0.05$ was considered to indicate a statistically significant difference. To perform statistical evaluation, each experiment, except for western blot analysis which was performed twice, was performed three times.

\section{Results}

Screening of candidate miRNAs. Firstly, 1,749 miRNAs that targeted DCLK1 were identified using TargetScan Human. Using the Ingenuity Pathway Analysis miRNA Target Filter, candidate miRNAs whose target genes were associated with Notch Signaling, Wnt/ $\beta$-catenin signaling or $\mathrm{Wnt} / \mathrm{Ca}^{2+}$ signaling pathway were screened. Eventually, 30 candidate miRNAs were selected for cell viability assessment (Fig. S1A). For the assessment, a CSC model was constructed by transducing ODC-degron to the pancreatic cancer Panc-1 cells as previously described (32-34) to test the effects of these miRNAs on stem [degron (+)] cells and non-stem [degron (-)] cells. miR-34a, which reached phase I clinical trial as a therapy for human solid tumors (5), was used as a therapeutic control in this experiment. Among the 30 miRNAs, miR-1291 (the 16th miRNA) markedly suppressed both the stem [degron (+)] and non-stem [degron (-)] viability of Panc-1 cells compared with either miR-NC or positive control miR-34a (Fig. S1B). This result is consistent with previous studies reporting that miR-1291 presented anti-tumor function in pancreatic cancer $(42,43)$. However, functional assessment of miR-1291 in $\mathrm{CRC}$ has not been conducted, and therefore it was investigated in the present study whether miR-1291 would be a therapeutic option against CRC.

Expression of miR-1291 in CRC cells and clinical tissue specimens. The expression of miR-1291 was evaluated in nine CRC cell lines and three non-tumor cell lines (293, CCD-18Co and MRC5) by RT-qPCR (Fig. 1A). The expression of miR-1291 in the nine CRC cell lines was generally lower when compared with the normal colon tissue cell lines. According to the tissue atlas database, miR-1291 levels in normal colon tissues is $1 / 50$ and 1/1,500 of putative anti-oncomiR miR-34a-5p and oncomiR miR-21-5p, respectively (Fig. S2). The expression levels of miR-1291 in normal mucosa and CRC tissues from 20 paired clinical tissue specimens were examined in the present study. The results revealed that miR-1291 expression was significantly lower in tumor tissues compared with normal mucosa (Fig. 1B). When the clinicopathological characteristics of tumors were assessed, there was no significant difference of the clinicopathological characteristics between high and low miR-1291 levels (Table SII).

miR-1291 overexpression after transfection. At 4 or $24 \mathrm{~h}$ after miRNA transfection, miR-1291-transfected cells presented markedly higher miR-1291 expressions compared with the miR-NC transfection group in DLD-1, HT29 and HCT116 cells (Fig. 2A).

In vitro tumor inhibitory effects of miR-1291. miR-1291 significantly suppressed cell viability compared with the miR-NC transfection group in DLD-1, HT29 and HCT116 cells after 48 and $72 \mathrm{~h}$ of transfection (Fig. 2B).

The invasion of cells was subsequently assessed at different time points since the time required for each cell type to pass through Matrigel is different, as previously reported $(53,58)$. These included incubations for 48, 72 and $96 \mathrm{~h}$ for DLD-1, HCT116 and HT29 cells, respectively. The invasion of miR-1291-transfected cells was significantly inhibited compared with miR-NC-transfected cells in the three cell lines examined (Fig. 2C). The effect of miR-1291 on the gap closure ability of CRC cells was then evaluated. The migration of cells was significantly suppressed in the miR-1291 group compared with the miR-NC group in 10\% FBS supplemented conditions (Fig. 3A). Furthermore, miR-1291 significantly inhibited the colony formation of cells compared with miR-NC (Fig. 3B). In repeat experiments the miR inhibitor (antagomir-1291) was additionally included as previously reported (59-61). It was revealed that the effects of miR-1291 on cell viability, invasion and migration were not observed when CRC cells were treated by antagomir-1291 (Fig. S3A-C). To further investigate the decrease in cell viability by miR-1291, BrdU proliferation assays and Annexin V apoptosis assays were performed. It was demonstrated that miR-1291 significantly suppressed the proliferation of DLD-1, HT29 and HCT116 cells at 24 and $48 \mathrm{~h}$ (Fig. 4A) and induced higher rates of apoptosis, especially in DLD-1 cells (Fig. 4B).

miR-1291 directly targets DCLK1. In silico analysis using TargetScan Human indicated that miR-1291 may directly bind to the 3'UTR of DCLK1 mRNA (Fig. 5A). Other miR databases, including miRwalk, miRabel and miRmap also supported that 
A
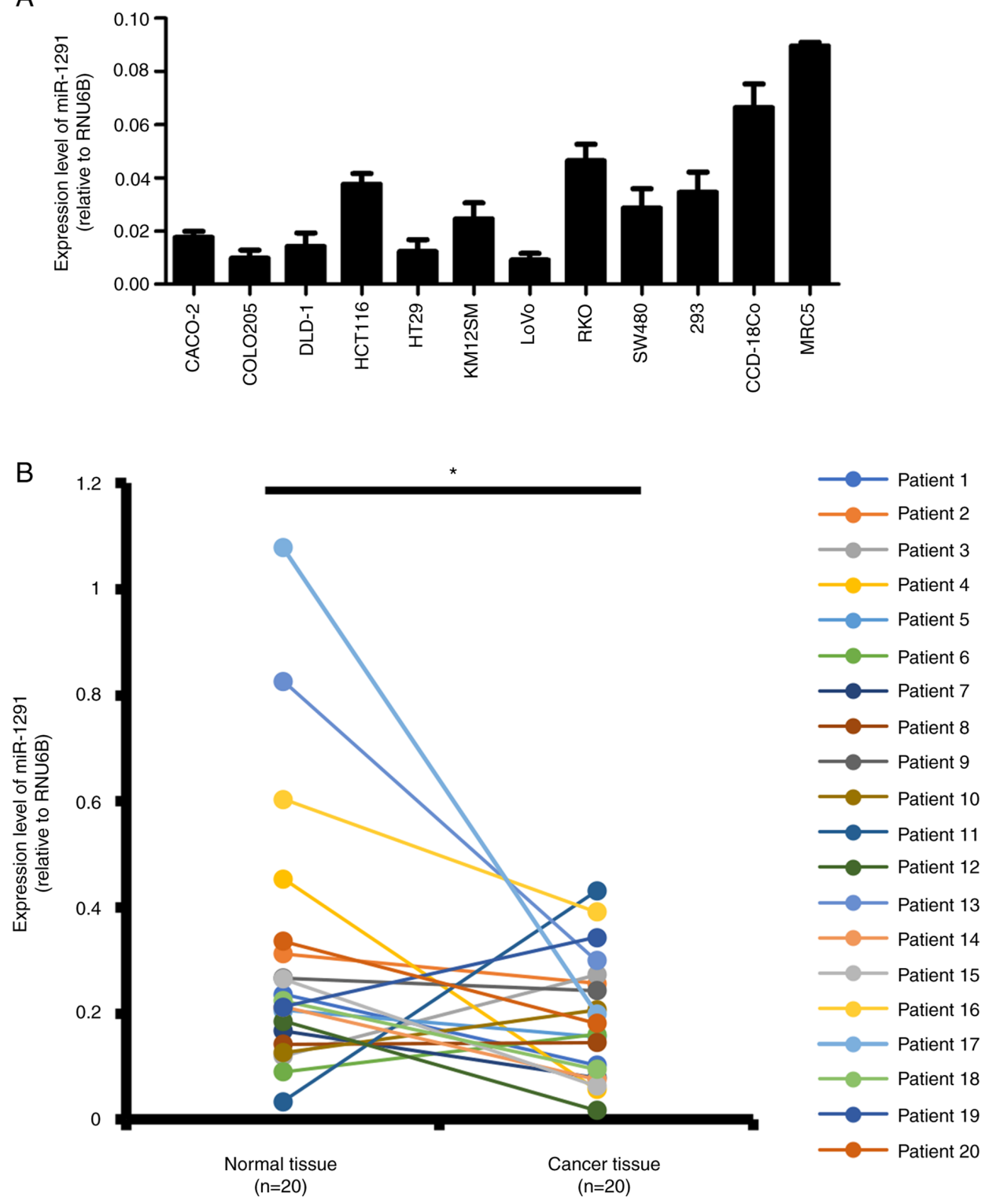

Figure 1. Expression levels of miR-1291. (A) CRC cell lines and non-tumor cell lines. Reverse transcription-quantitative PCR was used to detect the expression of miR-1291 in CRC cell lines (CACO-2, COLO205, DLD-1, HCT116, HT29, KM12SM, LoVo, RKO and SW480) and human non-tumor cell lines (293, CCD-18Co and MRC5). RNU6B was used as a loading control. All experiments were performed in triplicate. All data are presented as the mean \pm SEM. (B) Expression levels of miR-1291 were detected in CRC tissues and corresponding normal colon mucosa $(\mathrm{n}=20)$. Different colored lines represent the individual patient analyzed. $\mathrm{P}<0.05$ as indicated. CRC, colorectal cancer; miR, microRNA.

DCLK1 is a potential target of miR-1291. Therefore, luciferase reporter assays were performed to confirm whether miR-1291 could directly bind to DCLK1 mRNA. Co-transfection with miRNA-1291 at $50 \mathrm{nM}$ significantly inhibited the luciferase activity of wild type of the DCLK1-3'UTR reporter vector compared with miR-NC. However, no significant difference in luciferase activity was observed between miR-1291 and miR-NC groups following 2-nucleotide Mut or 3-nucleotide Del DCLK1-3'UTR reporter vector transfection (Fig. 5B). Our previous study on the role of DCLK1 in CRC revealed that HCT116 expressed the DCLK1 protein, but DLD-1 and HT29 did not (29). This result was confirmed in the present study (Fig. 5C). Transfection with miR-1291 significantly suppressed the expression of DCLK1 mRNA compared with miR-NC, and a repeat assay including antagomir-1291 demonstrated that antagomir-1291 had no inhibitory effects on DCLK1 mRNA expression (Fig. 5D and E). Transfection with miR-1291 also significantly decreased the expression of the short form of DCLK1 protein compared with miR-NC (Fig. 5F).

miR-1291 suppresses stem-like properties in HCT116 cells. It was then demonstrated that other CSC markers in addition to DCLK1, including BMI1 and CD133, were significantly downregulated by miR-1291 overexpression at the mRNA level (Fig. 6A). In addition, the ratio of CD133, but not CD166, positive cells decreased following miR-1291 transfection, as revealed by flow cytometric analysis (Figs. 6B and S4). Western blotting also indicated that CD133 protein expression was significantly decreased by miR-1291 treatment compared with miR-NC transfection (Fig. 6C). Furthermore, miR-1291 treatment significantly decreased the sphere formation of HCT116 cells, which is a hallmark of CSC (24,33) (Fig. 6D). 
A

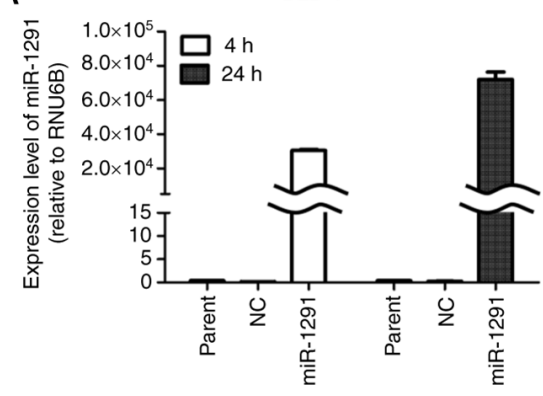

B

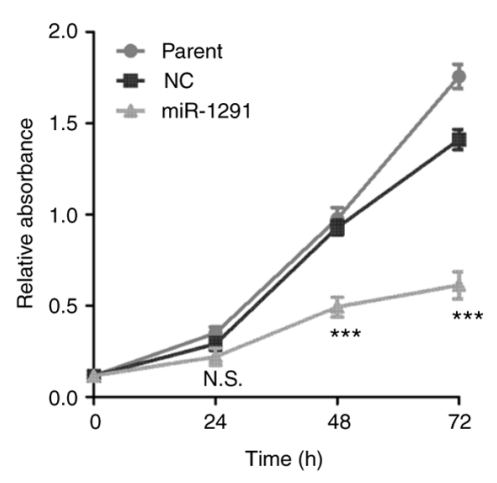

HT29

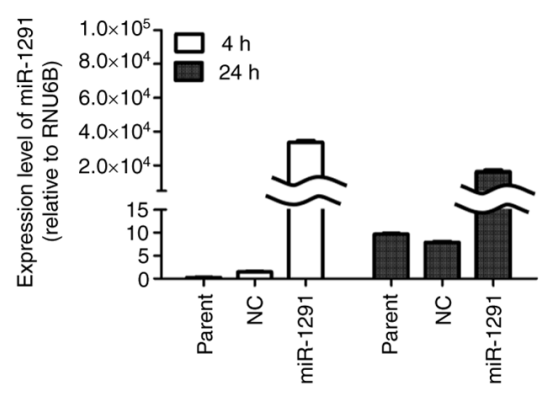

HT29

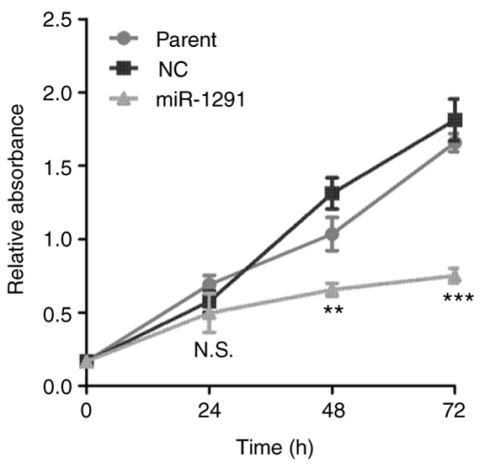

HCT116

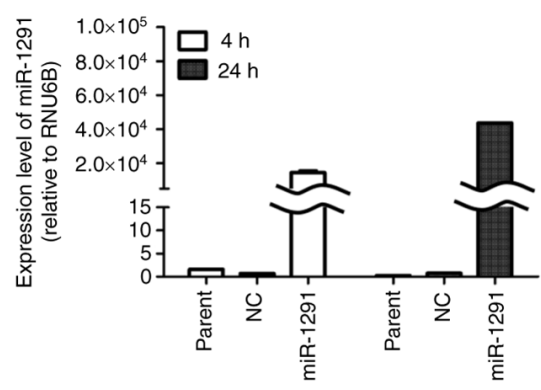

HCT116

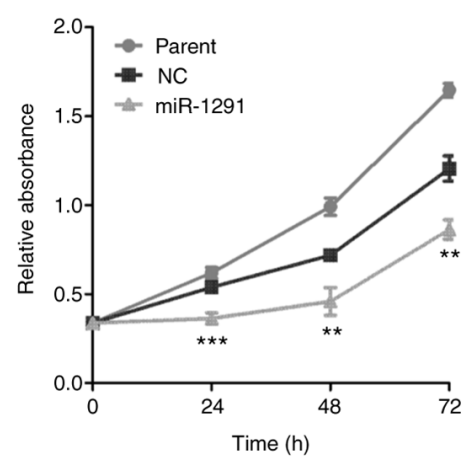

HCT116
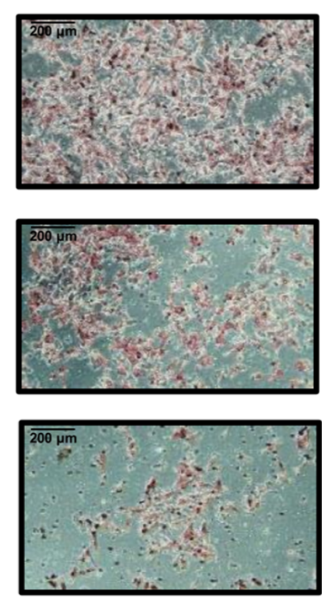

HCT116

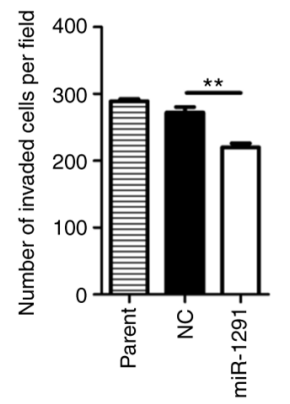

Figure 2. Inhibition of colorectal cancer cell malignancy by miR-1291. (A) miR-1291 levels were recorded at 4 or $24 \mathrm{~h}$ after miR-1291 and miR-NC transfection. RNU6B was used as an internal control. (B) The viability of DLD-1, HT29, and HCT116 cells was detected following miR-1291 overexpression. (C) Invasion was assessed using the Matrigel Invasion Chambers. For DLD-1 and HCT116 cells, $1 \times 10^{5}$ cells/chamber were seeded and $2 \times 10^{5}$ cells/chamber were seeded for HT29 cells. Invasive cell numbers were counted at 48, 72 and $96 \mathrm{~h}$ after transfection. All experiments were performed in triplicate. All data are presented as the mean \pm SEM. ${ }^{*} \mathrm{P}<0.05,{ }^{* *} \mathrm{P}<0.01$ and ${ }^{* * *} \mathrm{P}<0.001$ as indicated. miR, microRNA; NC, negative control; N.S., not significant.

To verify the functional role of DCLK1 in sphere formation of HCT116, siRNAs (siRNA1, siRNA2 and siRNA3) were used to knock down DCLK1. Western blot analyses revealed that the protein expression of DCLK1 decreased by these three siRNAs (Fig. 6E), and that siRNA transfection significantly downregulated sphere formation in HCT116 cells (Fig. 6F) 

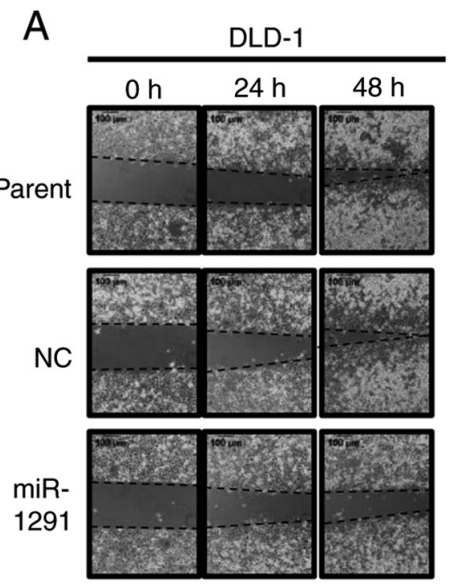

DLD-1 $48 \mathrm{~h}$

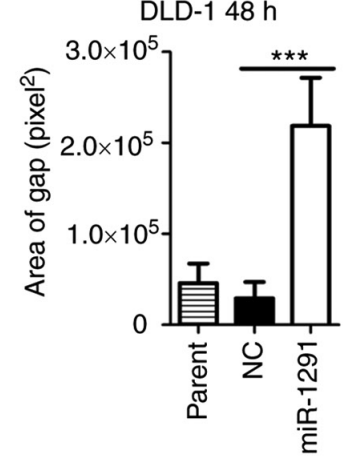

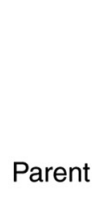
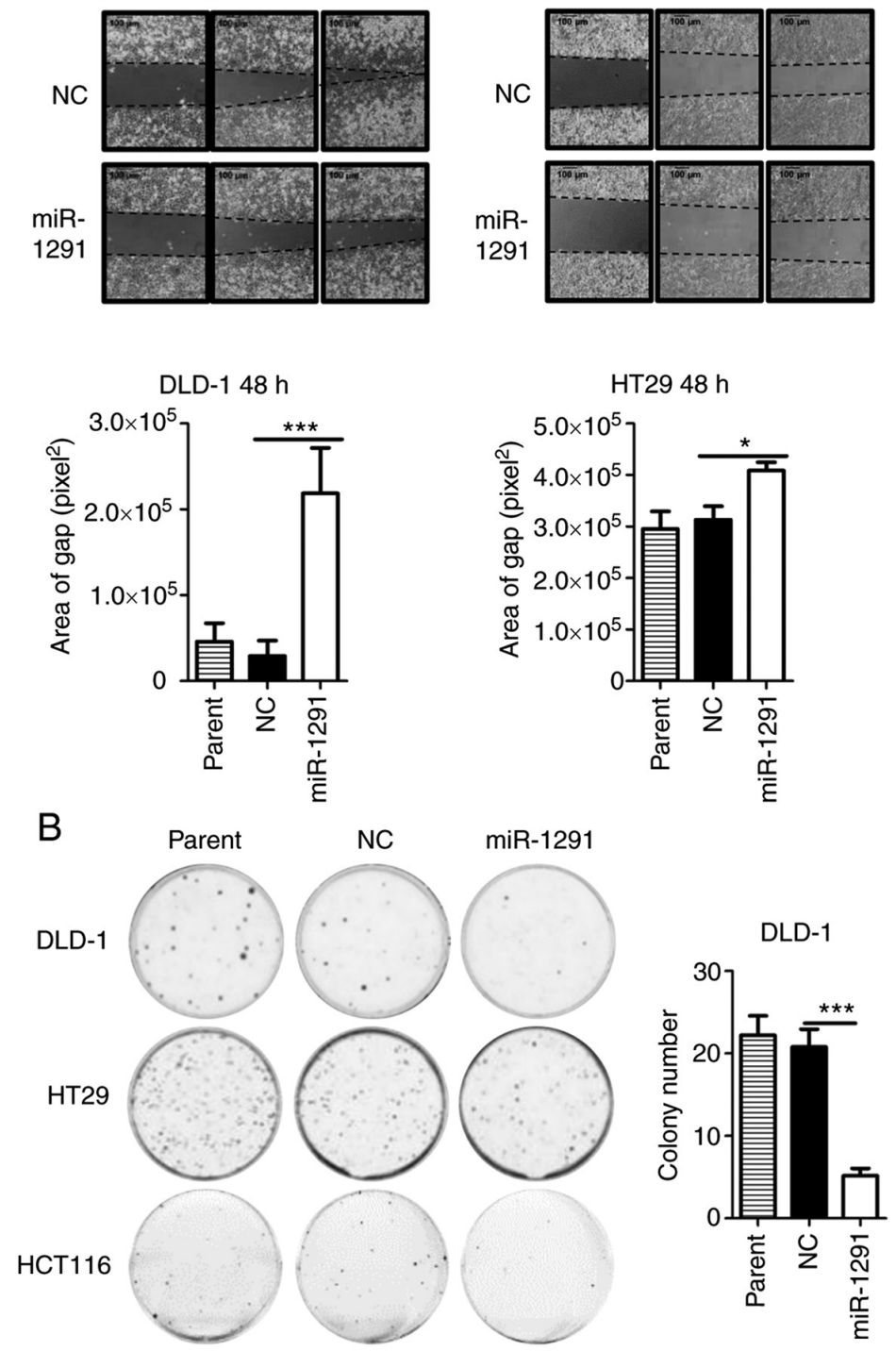

HT29 $48 \mathrm{~h}$
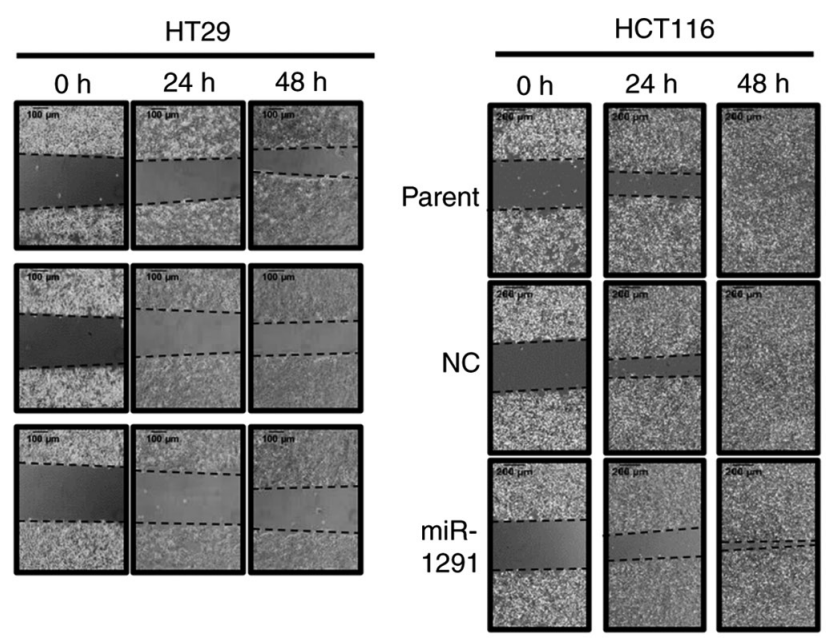

HCT116 $24 \mathrm{~h}$

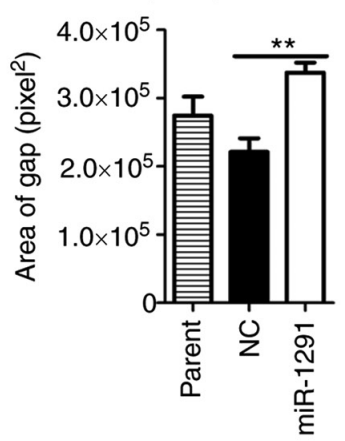

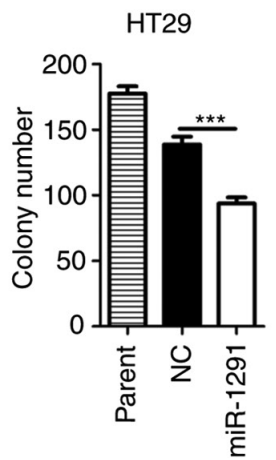

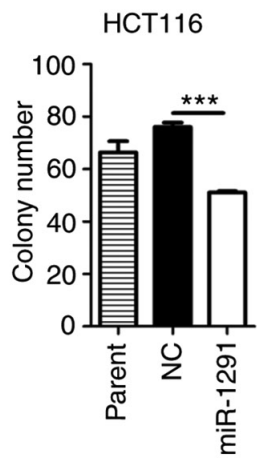

Figure 3. Inhibition of colorectal cancer cell gap closure and colony formation by miR-1291. (A) Gap closure assay in DLD-1, HT29 and HCT116 cells treated with miR-NC or miR-1291. The area of gap (unit, pixel ${ }^{2}$ ) was assessed 0,24, and $48 \mathrm{~h}$ by ImageJ $1.52 \mathrm{v}$ software. (B) The colony formation of DLD-1, HT29 and HCT116 cells was subsequently assessed 10 days after transfection with miR-1291. All data are presented as mean \pm SEM. ${ }^{*} \mathrm{P}<0.05,{ }^{* *} \mathrm{P}<0.01$ and ${ }^{* * * *} \mathrm{P}<0.001$ as indicated. miR, microRNA; NC, negative control.

compared with miR-NC-treated group. Furthermore, it was verified that shDCLK1 clones, which were produced in our previous study (29), exhibited decreased sphere formation in HCT116 cells compared with sh-NC cells (Fig. 6G).

In vitro tumor inhibitory effects of DCLK1 siRNAs. The effects of DCLK1 siRNAs on cell viability, invasion and gap closure were examined. DCLK1 siRNAs significantly suppressed the migration and invasion of HCT116 cells. For the effects on cell viability, although miR-1291 significantly decreased the viability of HCT116 cells at 48 and $72 \mathrm{~h}$ (Fig. 7A), only one of the DCLK1 siRNAs (siRNA1) significantly suppressed the cell viability at $72 \mathrm{~h}$ after transfection compared with the miR-NC
(Fig. 7A). However, DCLK1-siRNA significantly suppressed the invasion and gap closure of HCT116 cells compared with miR-NC groups (Fig. 7B and C).

Altered expression of cell cycle components by treatment of miR-1291. Since DLD-1 and HT29 cells had no or scarce DCLK1 expression (Fig. 5C), another mechanism should exist for miR-1291-mediated anti-tumor effect. Therefore, alterations of the cell cycle and cell cycle-related protein expressions were investigated. By performing cell cycle distribution analysis after cells were serum-starved, the results revealed that the G1-S population increased in DLD-1 cells at $12 \mathrm{~h}(60.81$ vs. $67.89 \%)$ and that the G2-M fraction increased 

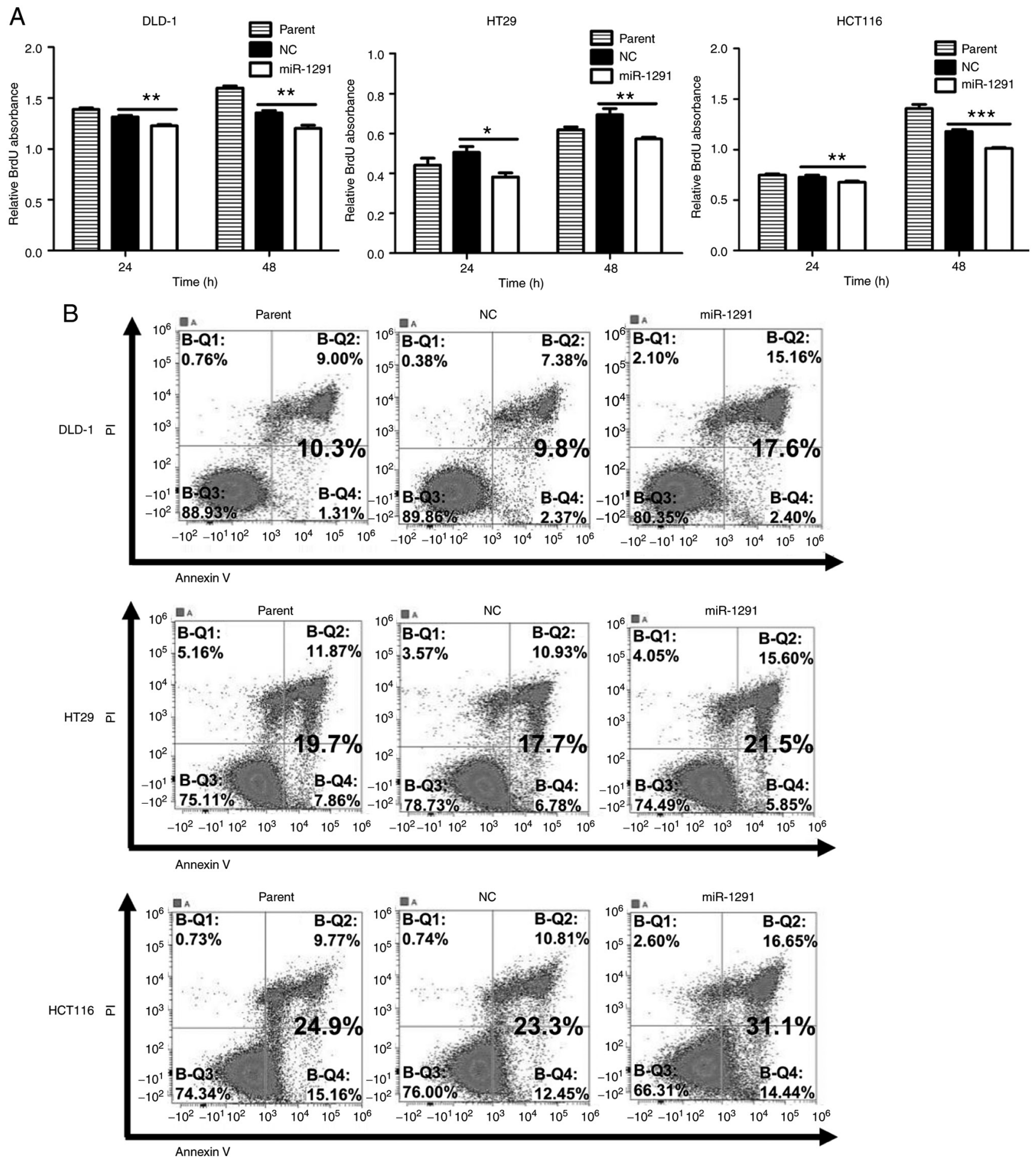

Figure 4. Treatment of miR-1291 inhibits cell proliferation and induces apoptosis. (A) The relative absorbance of BrdU (450/540 nm) was measured in DLD-1, HT29 and HCT116 cell lines at 24 and $48 \mathrm{~h}$ after transfection All experiments were performed in triplicate. All data represent the mean \pm SEM. (B) The percentage of apoptotic cells (in bold font in the center of the charts) were calculated by combining both the percentage of early apoptosis (Annexin $\mathrm{V}+$, $\mathrm{PI}-$; shown in B-Q2) and late apoptosis (Annexin V+, PI+; shown in $\mathrm{B}-\mathrm{Q} 4) .{ }^{*} \mathrm{P}<0.05,{ }^{* * *} \mathrm{P}<0.01$ and ${ }^{* * *} \mathrm{P}<0.001$ as indicated. BrdU, bromodeoxyuridine; miR, microRNA; NC, negative control.

in HT29 cells at $48 \mathrm{~h}(12.01$ vs. $17.21 \%)$ following treatment with miR-1291 when compared with the NC group (Fig. S5A). Western blot analyses indicated that the expression of CDK inhibitors $\mathrm{p} 21^{\mathrm{WAF} / \mathrm{CIP} 1}$ and $\mathrm{p} 27^{\mathrm{KIP} 1}$ were significantly upregulated in DLD-1, HT29 and HCT116 cells (Fig. 8A and B). Moreover, G1-S accelerators CDK4 (at $48 \mathrm{~h}$ ) and Rb (at $72 \mathrm{~h}$ ) in DLD-1 cells, CDK4 (at 48 and 72 h) in HT29 cells and CDK4 (at $72 \mathrm{~h}$ ) in HCT116 cells were downregulated. G2-M accelerators CDC25B (at $72 \mathrm{~h}$ ), along with CDC25C (at 48 and $72 \mathrm{~h}$ ), and phosphorylated-cdc2/cdc2 ratio (at $48 \mathrm{~h}$ ) also decreased in HT29 cells (Fig. S5B). In addition, it was identified that the DCLK1-overexpressing HCT116 clone expressed considerably higher levels of short form DCLK1 protein at $48 \mathrm{~h}$ after transfection compared with parental cells or empty vector 
A Mutation

DCLK1 $3^{\prime}$ UTR WT $\quad 5^{\prime} \ldots$ GCAGCUCAGAAGAAUGCAGGGCCC...3 (Position 2459-2465) miR-1291 3' UGACGACCAGAAGUCAGUCCCGGU 5'

| | |||

DCLK1 3' UTR Mut $5^{\prime}$... GCAGCUCAGAAGAAUGCUCGGCCC....3'

Deletion

DCLK1 3' UTR WT $5{ }^{\prime} \ldots$ GCAGCUCAGAAGAAUGCAGGGCCC...3 (Position 2459-2465)

miR-1291 $3^{\prime}$ UGACGACCAGAAGUCAGUCCCGGU 5

Seed sequence

I| ||

DCLK1 3' UTR Del 5' ...GCAGCUCAGAAGAAUGCA---CCC...3'

B

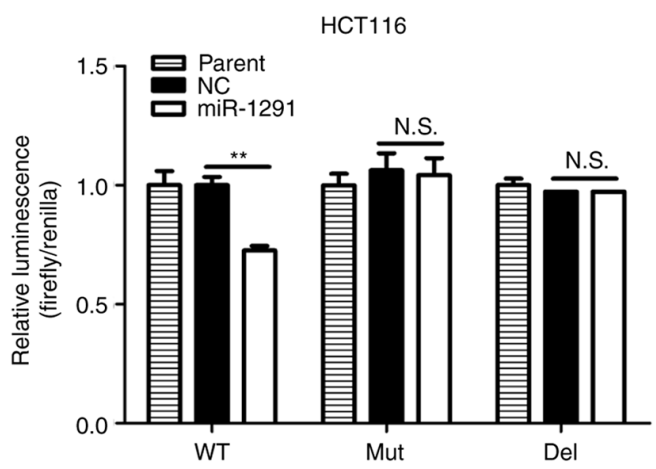

C

C DLD-1 HT29 HCT116

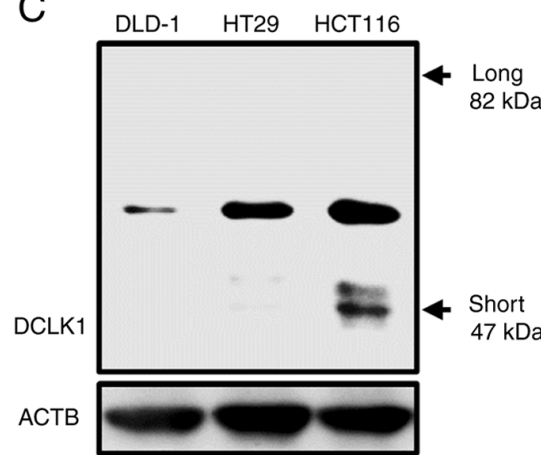

D

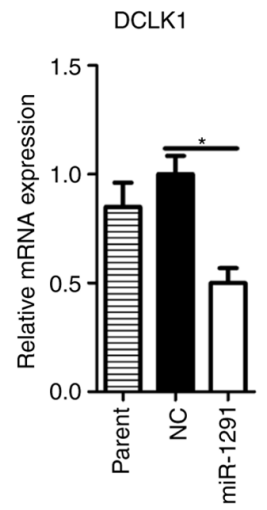

$\mathrm{E}$

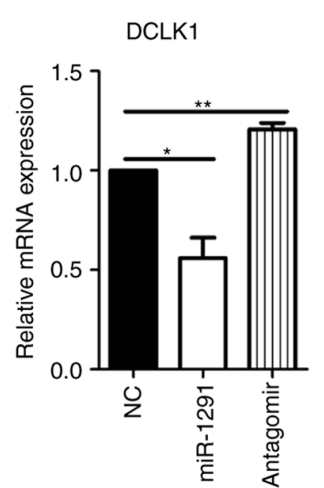

F
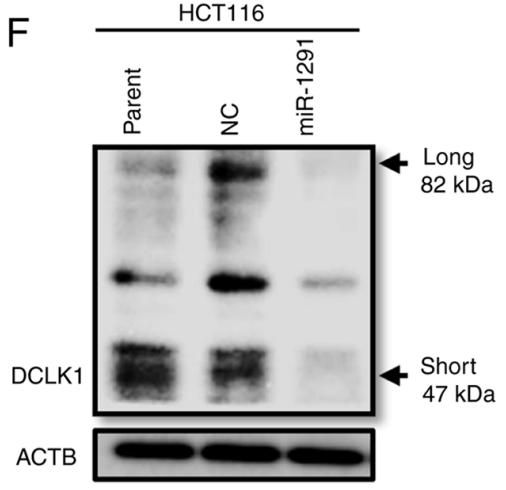

DCLK1

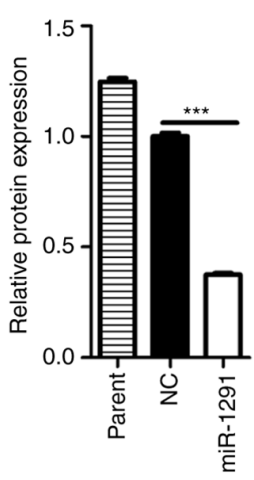

Figure 5. miR-1291 directly targets the 3'UTR of DCLK1 in HCT116 cells. (A) TargetScan (http://www.targetscan.org/vert_72/) was used to identify a binding site at position 2,459-2,465 of the DCLK1 mRNA 3'UTR that was complementary to the seed sequence of miR-1291 (WT). The binding sequence of DCLK1 was mutated by changing two nucleotides (Mut) or deleting three nucleotides (Del). (B) A luciferase reporter assay was performed in HCT116 cells following transfection with miR-1291. (C) DCLK1 expression in HCT116 cells was assessed using an anti-human rabbit polyclonal antibody against DCAMKL1. (D) The effect of miR-1291 on the expression of DCLK1 was assessed by RT-qPCR. (E) A repeat RT-qPCR experiment was performed using antagomir-1291. GAPDH was utilized as an endogenous control. All experiments were performed in triplicate. All data are presented as the mean \pm SEM. (F) Western blotting was performed to determine the expression of DCLK1 protein after $48 \mathrm{~h}$ of transfection in HCT116 cells. Anti-human rabbit polyclonal antibodies against DCAMKL1 were used. ACTB was used as a loading control and two independent experiments were performed. ${ }^{*} \mathrm{P}<0.05$, ${ }^{* *} \mathrm{P}<0.01$ and ${ }^{* * * *} \mathrm{P}<0.001$ as indicated. Del, deletion; DCLK1, doublecortin-like kinase 1; miR, microRNA; Mut, mutant; NC, negative control; N.S., not significant; RT-qPCR, reverse transcription-quantitative PCR; UTR, untranslated region; WT, wild type.

transfected control cells. The expression of $\mathrm{p} 21^{\mathrm{WAF} 1 / \mathrm{CIP} 1}$ and $\mathrm{p} 27^{\mathrm{KIP} 1}$ protein decreased in the DCLK1-OE clone compared with parental or control cells (Fig. 8C).

Anti-tumor effects of miR-1291 in vivo. A DLD-1 tumor xenograft mouse model was used to verify the anti-tumor effect of miR-1291 in vivo. Compared with miR-NC group or parent group, the systemic administration of miR-1291 on sCA significantly inhibited the growth of tumors (Fig. 9A). No obvious body weight loss of mice was observed among the three groups (Fig. 9B). Western blotting using the resultant tumors indicated that the systemic administration of miR-1291 led to significant upregulation of $\mathrm{p} 21^{\mathrm{WAF} 1 / \mathrm{CIP} 1}$ and $\mathrm{p} 27^{\mathrm{KIP} 1}$ compared with miR-NC treatment (Fig. 9C).

\section{Discussion}

miRNA is emerging as a next generation cancer treatment (62-65). Previous studies have revealed that miR-1291 has anti-tumor effects in multiple types of cancer, including hepatocellular carcinoma, renal, esophagus, pancreatic and prostate cancer (39-46). The present study revealed that miR-1291 inhibited the viability of cancer stem-like pancreatic cancer cells. As for CRC, which is one of the most 

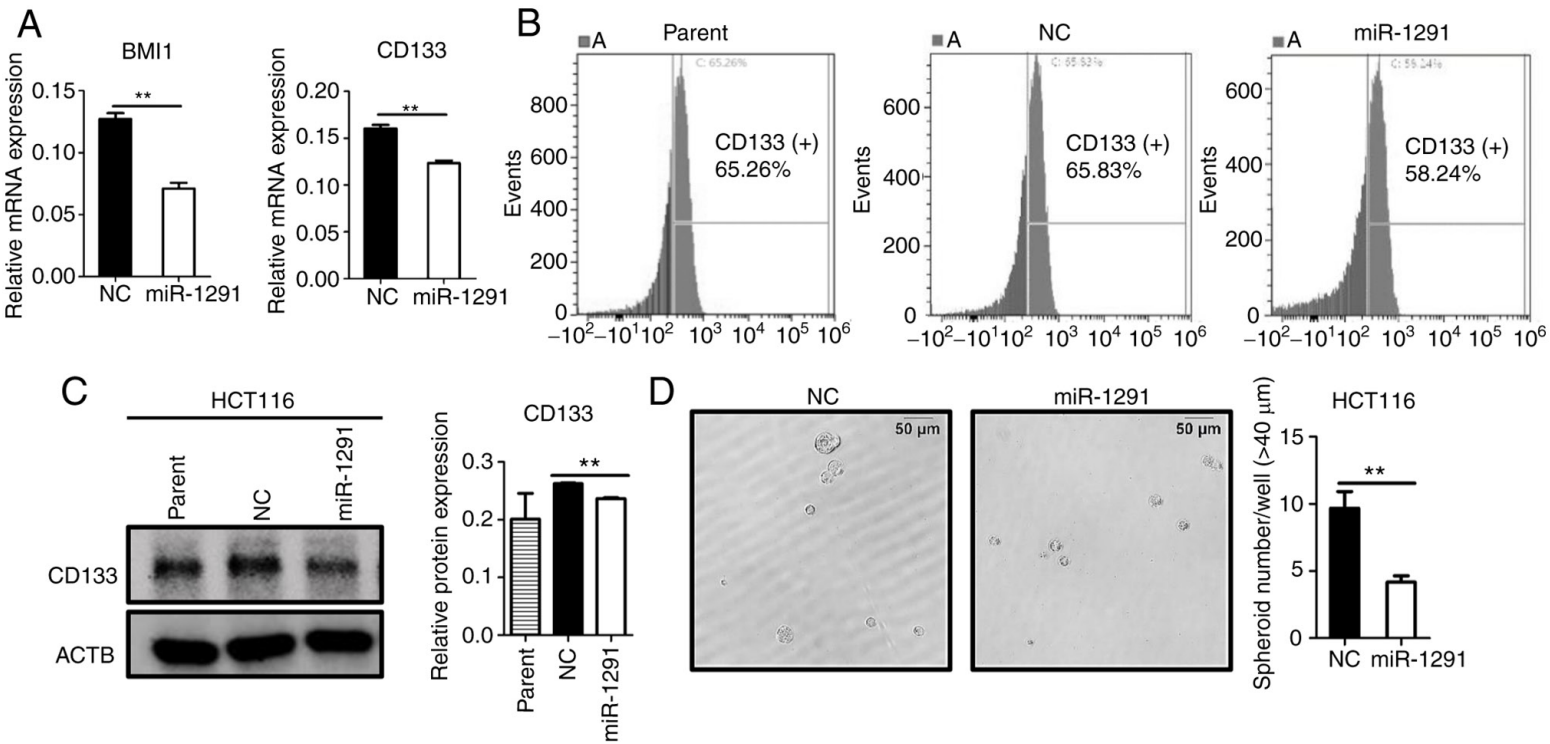

D NC
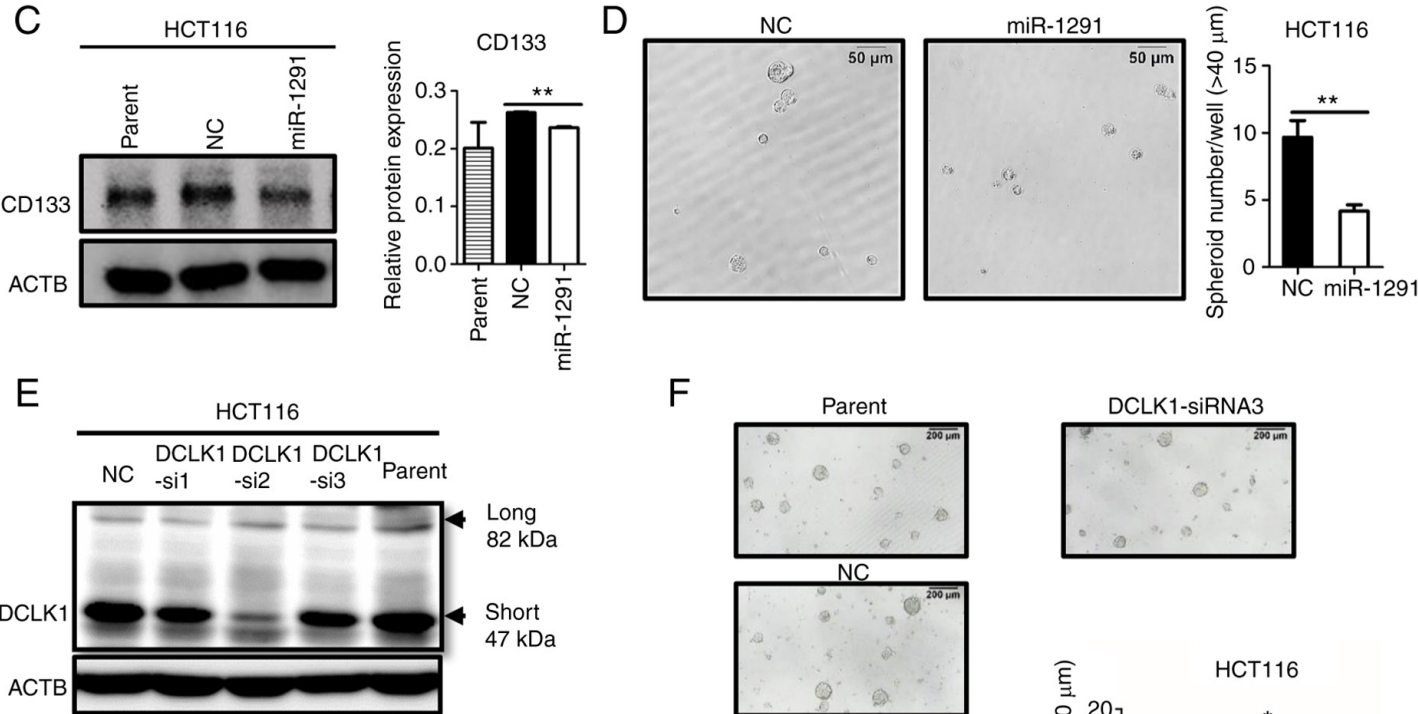

$\mathrm{F}$

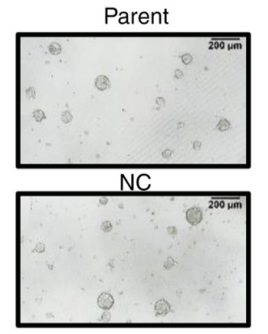

DCLK1-SiRNA1
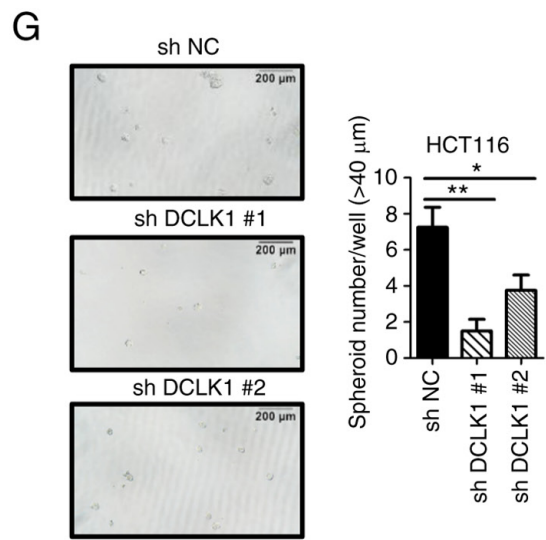
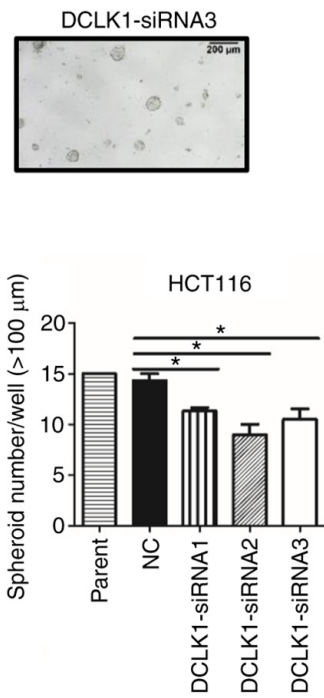

Figure 6. miR-1291 suppresses the stemness of HCT116 cells. (A) Reverse transcription-quantitative PCR was performed to evaluate stemness. GAPDH was utilized as an endogenous control. (B) Flow cytometric analysis was performed to determine the ratio of stem cell surface marker CD133 following miR-1291 and miR-NC transfection. (C) Western blotting was performed to determine the protein expression of CD133 following miR-1291 and miR-NC transfection. (D) Sphere formation ability was assessed in miR-1291-transfected HCT116 cells. The number of spheres $>40 \mu \mathrm{m}$ was counted 4 days after seeding. Representative images are presented. (E) The effects of three siRNAs targeting DCLK1 were assessed via western blotting in HCT116 cells. Anti-human rabbit polyclonal antibodies against DCAMKL1 were used with ACTB as a loading control. (F) The number of spheroids ( $>100 \mu \mathrm{m})$ following DCLK1-siRNA transfection was counted at day 7 after seeding. (G) Spheroid formation of shDCLK1 clones. All experiments were performed in triplicate. All data are presented as the mean \pm SEM. ShDCLK1 clones of HCT116 were generated in our previous study (29). "P<0.05 and ${ }^{* *} \mathrm{P}<0.01$ as indicated. DCLK1, doublecortin-like kinase 1; miR, microRNA; NC, negative control; si-, small interfering; sh-, short hairpin.

widespread cancers in the world, Salehi et al (47) analyzed 14 paired primary CRC samples and liver metastasis samples using NCBI GEO database. It was reported that miR-1291 only demonstrated a 1.065 -fold increase $(\log F C 0.0895)$ in liver metastasis compared with primary CRC samples among 58 upregulated miRNAs. By using TargetScan, it was also suggested that DCLK1 may be a potential target of miR-1291. In the present study, the direct binding of miR-1291 to DCLK1 mRNA was verified and functional in vitro and in vivo assessments of miR-1291 were performed in CRC cells.

The tissue atlas database has indicated that miR-1291 levels in colon tissue are relatively low, at $\sim 1 / 50$ and 1/1,500 of the putative anti-oncogenic miR-34a and the oncogenic miR-21 (5), respectively. In the present study, it was revealed that miR-1291 expression in CRC cell lines was generally lower compared with the colon tissue cell line CCD-18Co. However, the absence of the other normal human colon cell 

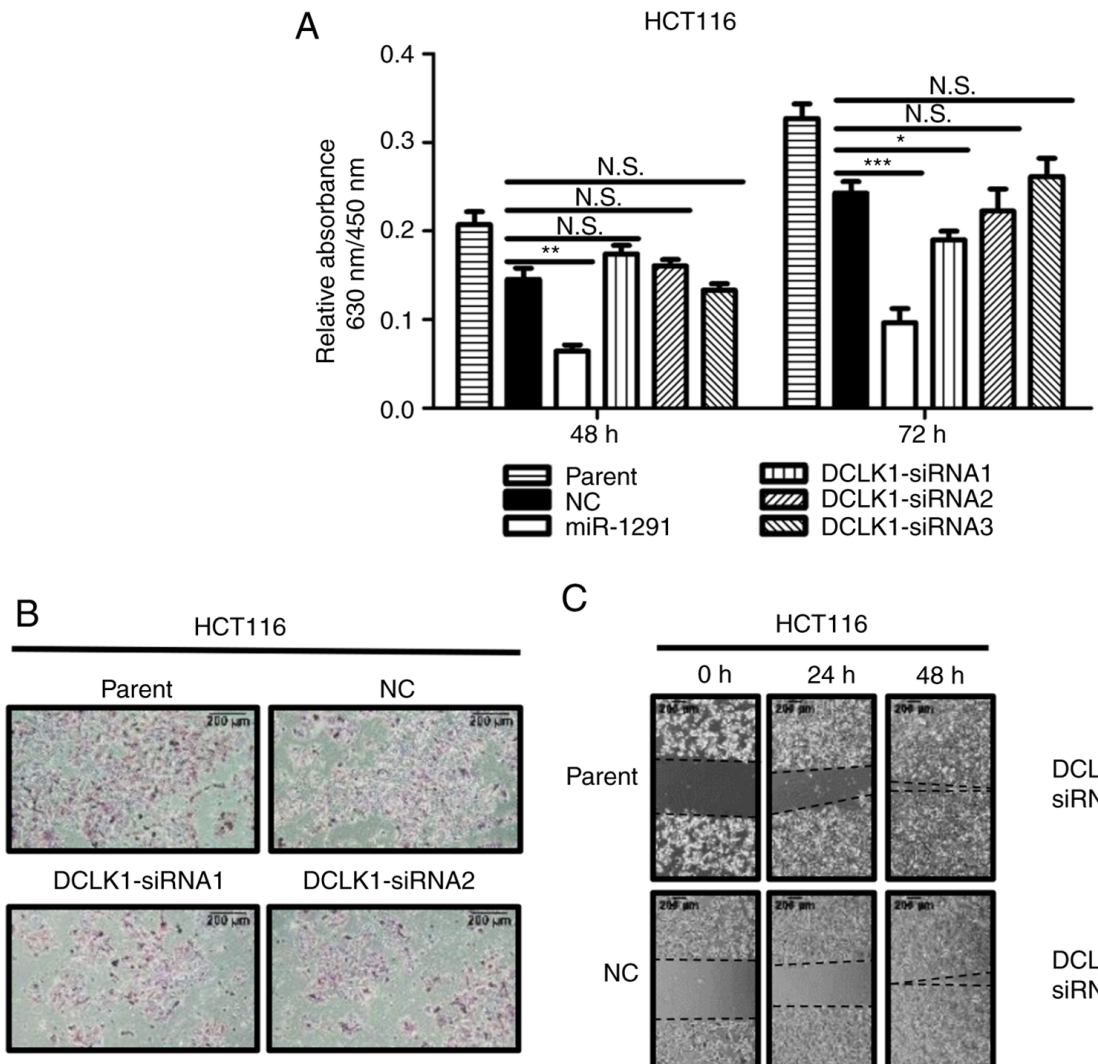

C
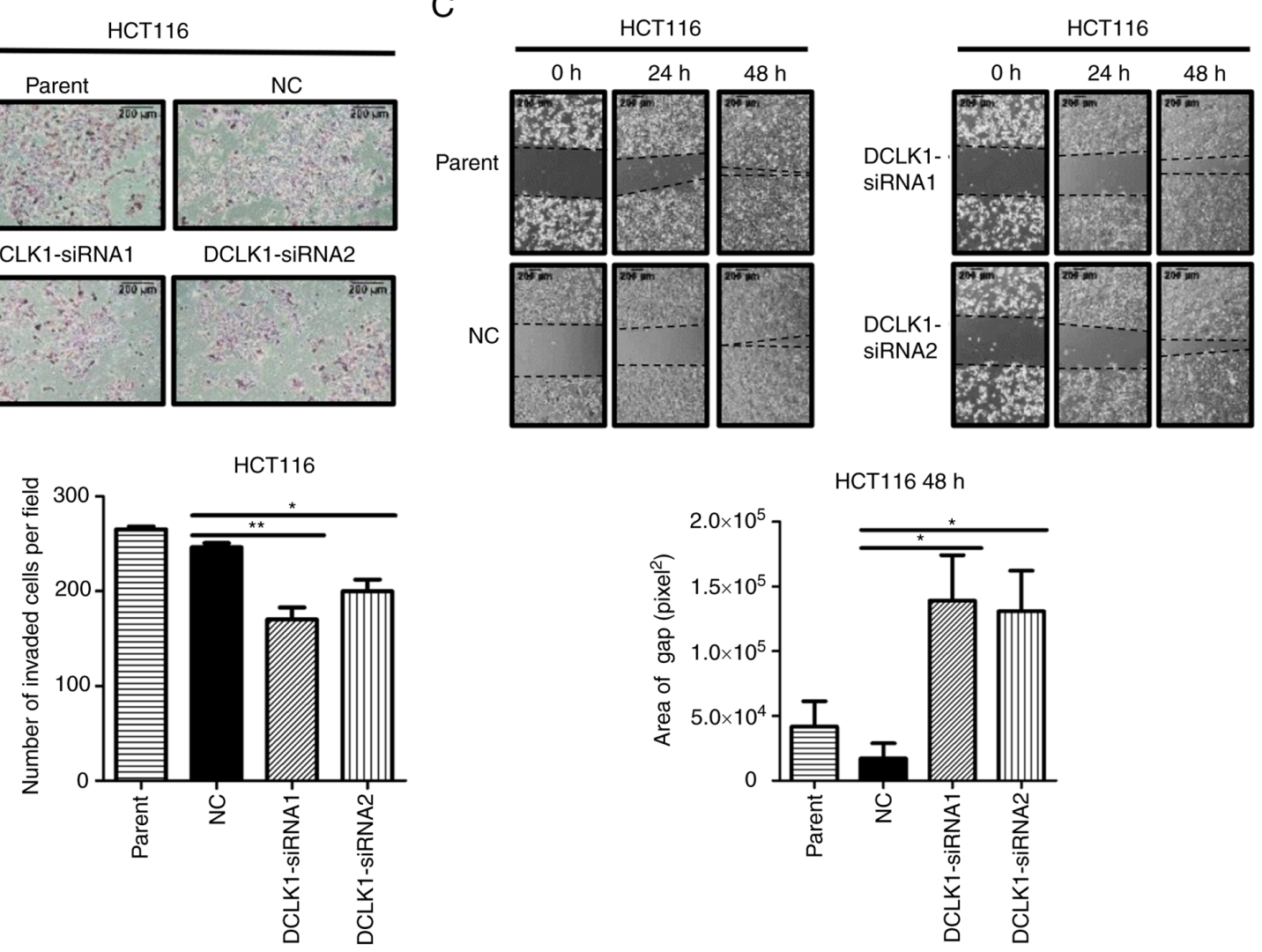

Figure 7. Effect of DCLK1-siRNAs on the viability, invasion and gap closure of HCT116 cells. (A) HCT116 cells were treated with miR-1291 or DCLK1-siRNAs at a concentration of $30 \mathrm{nM}$ for 48 and $72 \mathrm{~h}$. Cell viability was assessed by Cell Counting Kit- 8 assay. (B) HCT116 cell invasion was assessed following $50 \mathrm{nM}$ DCLK1-siRNAs transfection at $72 \mathrm{~h}$. BD BioCoat Matrigel invasion chambers (BD Biosciences) were used. (C) The gap closure ability of HCT116 cells was observed by transfection of DCLK1-siRNA1 and DCLK1-siRNA2 at concentration of $30 \mathrm{nM}$. The area of gap (unit, pixel ${ }^{2}$ ) was assessed at 0,24 and $48 \mathrm{~h}$ by ImageJ $1.52 \mathrm{v}$ software. All experiments were performed in triplicate. All data represent the mean $\pm \mathrm{SEM}$. ${ }^{*} \mathrm{P}<0.05,{ }^{* * *} \mathrm{P}<0.01$ and ${ }^{* * * *} \mathrm{P}<0.001$. DCLK1, doublecortin-like kinase 1 ; miR, microRNA; $\mathrm{NC}$, negative control; si-, small interfering.

lines, such as CCD-112CoN and CCD-33Co is a limitation of the present study. When comparing miR-1291 levels in normal and cancer colorectal tissues, it was found that cancer tissues expressed significantly lower levels of miR-1291 compared with normal mucosa. This result is in line with those of other cancer types, such as renal cell cancer, esophageal squamous cell cancer and prostate cancer (44-46), and emphasizes the tumor suppressive abilities of miR-1291. Furthermore, this situation is advantageous as miR-1291 is endogenously expressed in normal colorectal tissue, thus the restoration of tumor suppressive miR-1291 would be a relatively safe strategy for CRC treatment (17). When analyzing the relationship between with miR-1291 expression and various clinicopathological parameters, it was determined that miR-1291 levels were not associated with any clinicopathological factors in the present study. Further clinical study assessing a larger number of patients with CRC is therefore essential.

Each CRC cell line in the current study was used based on the representative characteristics of $\mathrm{CRC}$, and included: i) Cancer stem-like HCT116 cells (66-68); ii) differentiated carcinoma HT29 cells exhibiting goblet-like features (66); iii) aggressive phenotype DLD-1 cells obtained from a murine model displaying moderate to poorly differentiated adenocarcinoma (69). CRC is mostly composed of differentiated adenocarcinoma and $<5 \%$ 

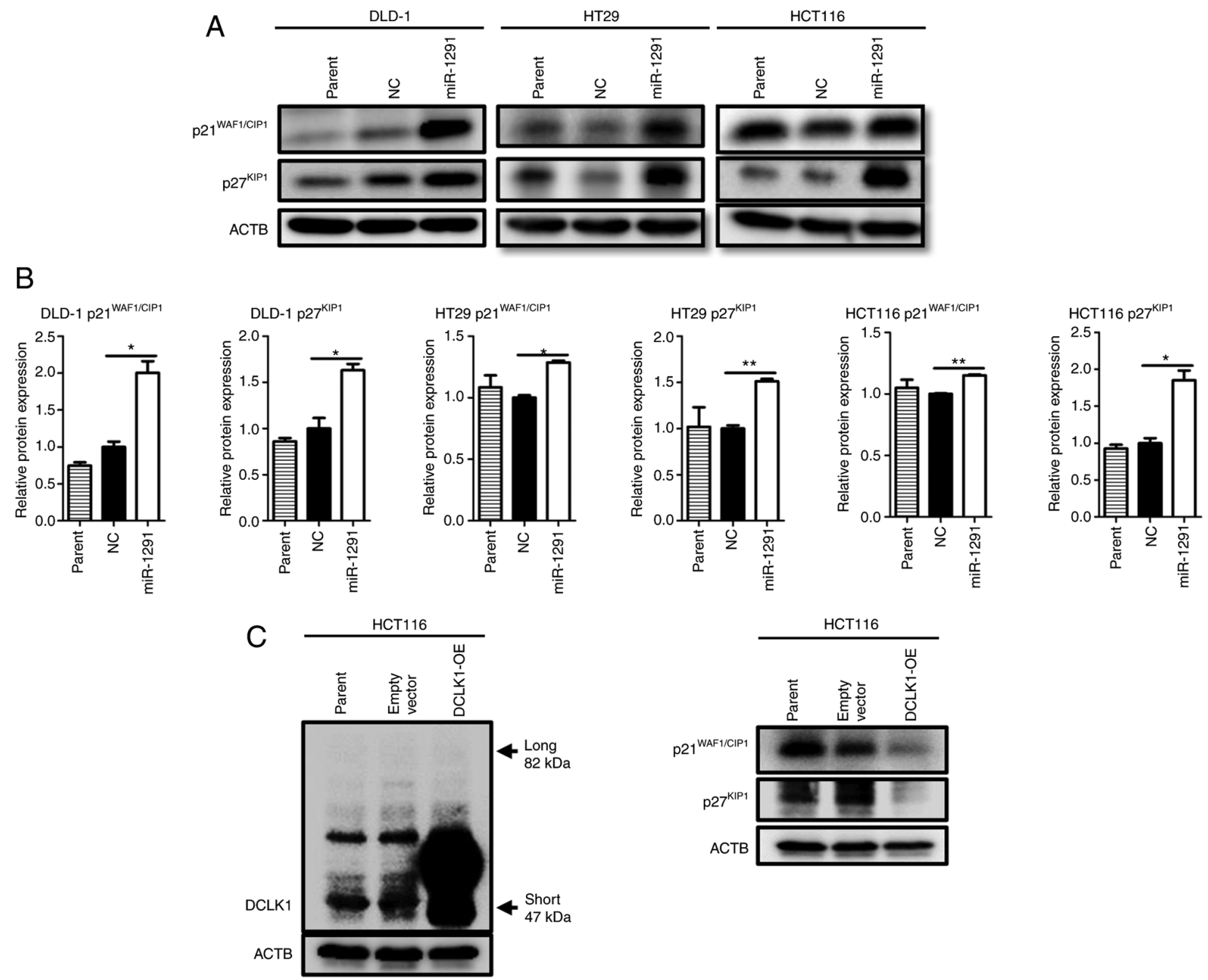

Figure 8. Cell cycle analysis. (A) The expression of cell cycle-related proteins was evaluated by western blotting. (B) Two independent experiments using rapid growing cultures evaluated the expression of $\mathrm{p} 21^{\mathrm{WAF} / \mathrm{CIPl}}$ and $\mathrm{p} 27^{\mathrm{KIPl}}$ in DLD-1, HT29 and HCT116 cells at $48 \mathrm{~h}$. ACTB was used as a loading control. (C) Western blotting for $\mathrm{p} 21^{\mathrm{WAF} / \mathrm{CIPl}}$ and $\mathrm{p} 27^{\mathrm{KIPl}}$ in DCLK1-OE HCT116 clones. DCLK1 cDNA was subcloned into the pcDNA3.1 plasmid, after which the DCLK1 vector or empty vector was transfected into HCT116 cells by Lipofectamine ${ }^{\circledast} 2000$. Cells were collected at $48 \mathrm{~h}$. ${ }^{*} \mathrm{P}<0.05$ and ${ }^{* *} \mathrm{P}<0.01$. DCLK1, doublecortin-like kinase 1; OE, overexpressing; miR, microRNA; NC, negative control.

of CRC is poorly differentiated carcinoma, which is extremely aggressive (1-3). CSC exists as a portion of the tumor population and is considered to be a cause of recurrence (22-24). HCT116 cells are considered to contain mainly CSCs since they do not differentiate or express transcription factor caudal-type homeobox 1 and since they have high colonosphere forming capacities (66-68). Additionally, $\mathrm{CD} 133^{+} \mathrm{CD} 44^{+}$stem-like cancer cells are highly enriched in HCT116 (68).

In the present study, it was revealed that miR-1291 was successfully transfected into three CRC cell lines between 4 and 24 h. miR-1291 levels reached $>1 \sim 5 \times 10^{4}$ fold higher than those of NC-treated cells. This result is in line with that of a previous study, which revealed that miR-522 levels were increased by $1 \sim 6 \times 10^{4}$ fold in ovarian cancer cell lines (70). In a previous time-course study, it was found that 18 mer oligo DNA was incorporated into 293 or HCT116 cell lines within $1 \mathrm{~h}$, with its peak effect being observed at $6 \mathrm{~h}$ and a gradual decline following thereafter (71). Small RNA sequences were also highly incorporated into various cell types at $4 \mathrm{~h}$ (52).

The present study demonstrated that miR-1291, but not antagomir-1291, exhibited anti-tumor effects in HCT116, DLD-1 and HT29 CRC cells with regard to cell proliferation, invasion, mobility, colony-forming and cell cycle regulation. The effect of miR-1291 should be compared with NC, but not with parental cells, because the transfection process itself occasionally causes stress or damage to the cells. This NC sequence was utilized and established in our previous studies (17,18,20,52-54). During fundamental in vitro assays, the negative control displayed data compatible with parental cells in most experiments.

Of the three CRC cell lines, DLD-1 was selected for in vivo experiments since miR-1291 exhibited the best efficacy in DLD-1 during in vitro experiments. DLD-1 is derived from a patient with colon cancer and the cells produce aggressive tumors in nude mice, as previously described (69), thus DLD-1 is also an important CRC cell line and has been used in our previous in vivo studies $(17,18,20)$. Previous studies have demonstrated that the intravenous administration of miR-1291 loaded on an sCA delivery system $(17,18,20,52-55)$ significantly inhibits the in vivo tumor growth of DLD-1 cells. It is of note that transfection efficiency when using an sCA system is markedly higher than when using a liposome system (52). Additionally, the sCA delivery system produces 

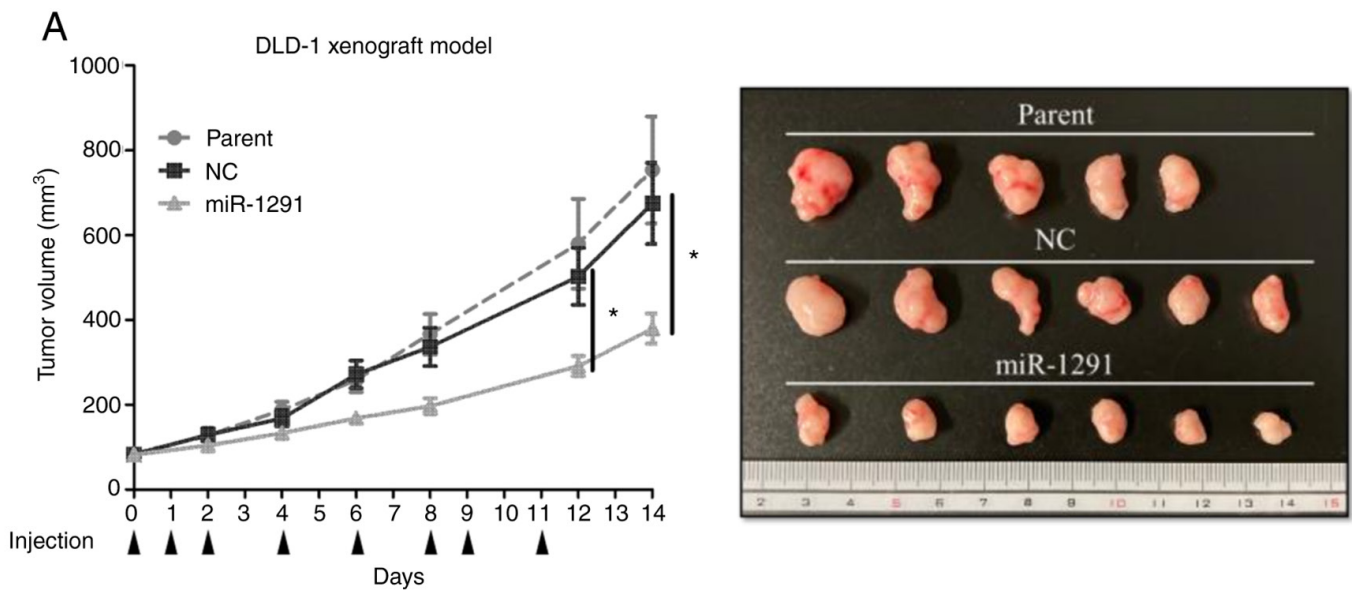

B

DLD-1 xenograft model

C
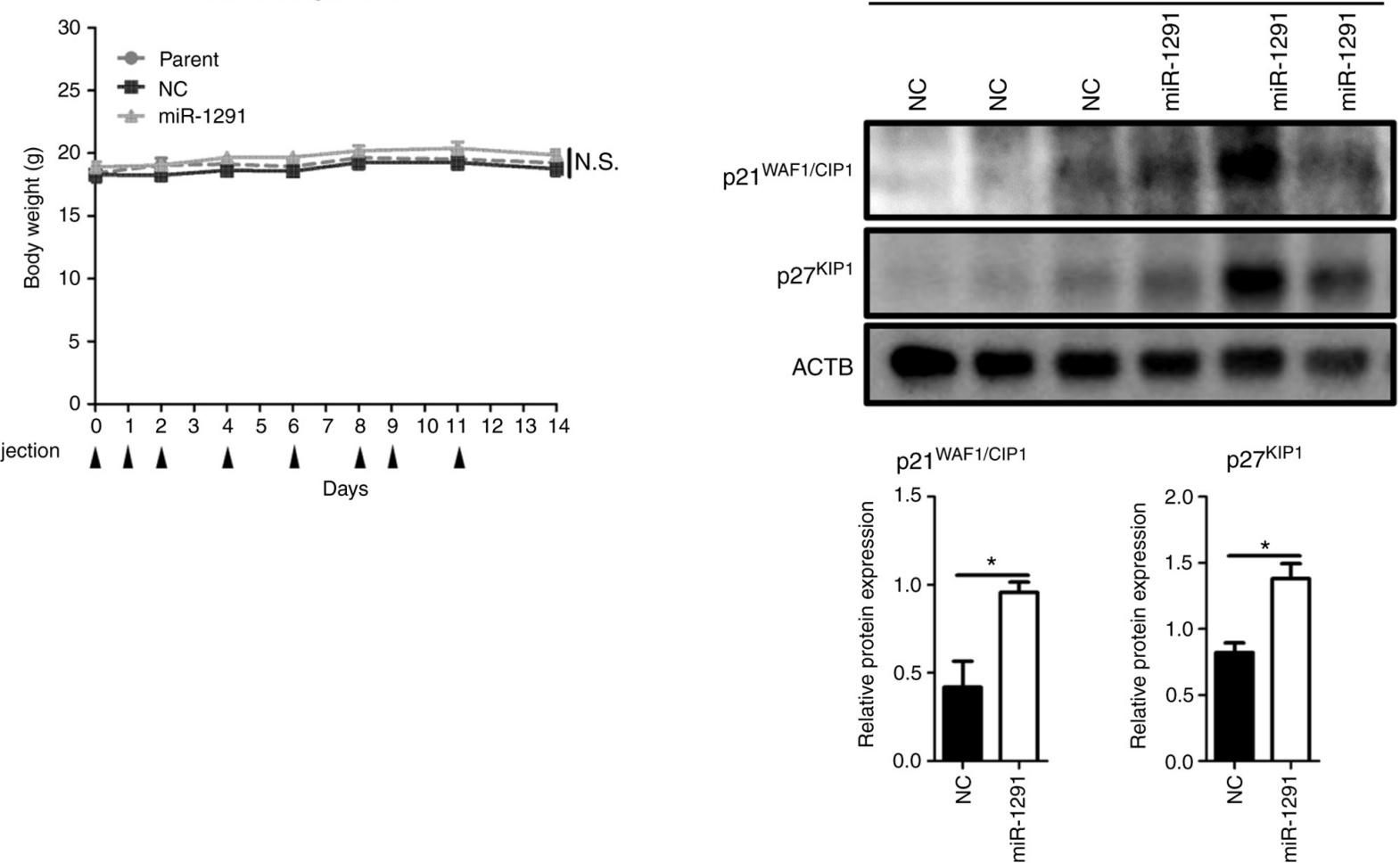

Figure 9. Systemic administration of formulated sCA-miR-1291 in vivo. (A) Tumor volume and images of resected tumors. When the mean tumor volume reached $80 \mathrm{~mm}^{3}$ (day 0), tumor xenograft mouse models received intravenous administrations of miR-1291 or miR-NC using sCA as a vehicle. This was administered on days $0,1,2,4,6,8,9$ and 11 via a tail vein injection (arrow heads indicate days of injections). Each injection contained $40 \mu \mathrm{g}$ of formulated oligo. Data are presented as the mean \pm SEM. (B) Body weight did not significantly differ between the groups. (C) Protein expression of cell cycle components in the tumors resected on day 14. ACTB was used as a loading control. ${ }^{~} \mathrm{P}<0.05$. sCA, super carbonate apatite; miR, microRNA; NC, negative control; N.S., not significant.

high uptake ( 500-1,500 fold higher miRNA levels) in tumor tissues $(18,20,54,55)$.

In the current study, miR-1291 inhibited the sphere formation of HCT116 cells, which is a hallmark of cancer stemness $(24,33)$. It has been reported that excision of DCLK1-positive CSC cells results in the regression of the intestinal tumor without apparent impairment of normal tissue, indicating that DCLK1 may be a novel target for CSC-targeted therapy (27). It was recently revealed that shDCLK1 clones, in which the expression of short form DCLK1 protein was silenced by shDCLK1 RNA, exhibited decreased cell growth, invasion, migration and EMT in HCT116 cells (29). The short form of DCLK1 is considered to play a crucial role in CRC. It has been demonstrated that the short form of DCLK1, but not the long form, is an important target for the suppression of CRC (72,73). Furthermore, patients with CRC exhibiting high expressions of short form, but not long form, DCLK1 tend to demonstrate a worse overall survival $(72,73)$.

The current study aimed to determine whether miR-1291 binds to 3'UTR of DCLK1 mRNA according to an in silico search using TargetScan and other databases. As a result, it was verified that miR-1291 directly bound to the 3'UTR of the DCLK1 mRNA sequence and that miR-1291, but not antagomir-1291, decreased DCLK1 mRNA expression in HCT116 cells in vitro. In silico analysis and in vitro selection revealed that miR-1291 was an upstream modulator of DCLK1. miR-1291 also decreased the expression of CSC markers BMI1 and CD133, but scarcely decreased CD166 expression $(25,26,68,74)$. Since these molecules are not likely to be direct targets of miR-1291 
according to TargetScan predictions, it is postulated that the decrease in BMI1 and CD133 may reflect certain diminution of the stem-like properties of HCT116 cells, which could be an indirect effect of miR-1291 through DCLK1.

DCLK1 siRNAs displayed relatively weak inhibition of cell viability, but exhibited potent anti-tumor effects in invasion and cell mobility assays. Additionally, DCLK1 siRNAs inhibited sphere formation, which was subsequently confirmed by shDCLK1 clones in HCT116 cells. The results regarding sphere formation are consistent with other studies, which demonstrated that DCLK1 levels were closely associated with spheroid formation in HCT116 cells (75,76). Taken together, it was suggested that miR-1291 may be involved in the regulation of stem cell properties through the inhibition of DCLK1 in HCT116 cells.

DLD-1 and HT29 cells, which express no or scarce DCLK1, exerted potent tumor inhibitory effects, suggesting that an additional mechanism may be operating in these CRC cells. In this regard, it is reported that miR-1291 regulates MUC1 in human esophagus cancer EC9706 and EC-1 cells (45). However, when MUC1 expression was examined with treatment of miR-1291 in CRC cells, its level was not decreased (unpublished data), suggesting that the target molecule may differ between tumor types. Instead, one of the major effects observed following miR-1291 treatment was the drastic increase in the cell cycle components $\mathrm{p} 21^{\mathrm{WAF} 1 / \mathrm{CIP} 1}$ and $\mathrm{p} 27^{\mathrm{KIP} 1}$. These CDK inhibitors bind to and block the G1-S accelerators Cyclin D1-CDK4/6 complex and Cyclin E1-CDK2 complex, leading to arrest from the G1 to $\mathrm{S}$ phase (77-79). In addition, $\mathrm{p} 21^{\mathrm{WAF} 1 / \mathrm{CIP} 1}$ has an ability to inhibit G2-M transition by inhibiting Cyclin B and cdc2 (80). Under conditions supplemented with FBS, no obvious change could be observed in the cell cycle distribution between miR-NC and miR-1291 treatment (unpublished data). However, following detailed cell cycle distribution analysis after cells were serum-starved, it was found that the G1-S population increased in DLD-1 cells at $12 \mathrm{~h}$ and that the G2-M fraction increased in HT29 cells at $48 \mathrm{~h}$ with treatment of miR-1291 compared with NC treatment. Accordingly, western blotting indicated downregulation of G1-S accelerators CDK4 in DLD-1 cells, HT29 cells and HCT116 cells. G2-M accelerators CDC25B, along with $\mathrm{CDC} 25 \mathrm{C}$, and phosphorylated-cdc $2 / \mathrm{cdc} 2$ ratio decreased in HT29 cells. In vivo experiments also revealed that systemic administrations of miR-1291 led to an upregulation of $\mathrm{p} 21^{\mathrm{WAF} 1 / \mathrm{CIP} 1}$ and $\mathrm{p} 27^{\mathrm{KIP} 1}$ in DLD-1 derived tumors. Although $\mathrm{p} 27^{\mathrm{KIP} 1}$ protein levels differed among the treated tumors, this is not unique, as the cell cycle during in vivo treatment could be affected by several factors such as tumor size, tumor vascularization and stromal development. Collectively, these findings suggested that miR-1291 could cause dysregulation of cell cycle control, which may partially account for mechanism underlying the anti-tumor effect of DLD-1 and HT29 cells. Although the precise mechanism is yet to be fully elucidated, DCLK1 in HCT116 cells may also be involved in the regulation of the CDK inhibitors, since it was determined that the overexpression of DCLK1 decreased $\mathrm{p} 21^{\mathrm{WAF} 1 / \mathrm{CIP} 1}$ and $\mathrm{p} 27^{\mathrm{KIP} 1}$ protein expression.

In conclusion, miR-1291 presented a potent anti-tumor effect in CRC cells. Furthermore, miR-1291 could suppress cancer stemness in HCT116 cells. To the best of our knowledge, this is the first study that conducted detailed functional assessments of miR-1291 in CRC. Considering the anti-tumor effect of miR-1291 in the broad range of cancer types (39-46), this miRNA may be a candidate for next generation nucleic acid medicine. Furthermore, it is also expected to serve as a CSC-targeted therapeutic strategy for DCLK1-expressing CRC when the practical drug delivery systems are equipped $(62-65,81,82)$.

\section{Acknowledgements}

The authors would like to thank Dr Masaaki Miyo (Department of Surgery, Gastroenterological Surgery, Graduate School of Medicine, Osaka University, Osaka, Japan.) for editing this manuscript, Dr Koki Takeda (Department of Surgery, Gastroenterological Surgery, Graduate School of Medicine, Osaka University, Osaka, Japan.) for technical advice and Professor Toshinari Minamoto (Cancer Research Institute, Kanazawa University, Kanazawa, Japan) for the generous gift of the KM12SM cell line. The authors would also like to thank Dr Frank Pajonk (Jonsson Comprehensive Cancer Center, UCLA, CA, USA) for providing the retroviral expression vector pQCXIN-ZsGreen-cODC containing green fluorescence ZsGreen-labeled degron ODC (Gdeg).

\section{Funding}

The present study was supported by a grant from Kagoshima Shinsangyo Sousei Investment Limited Partnership (its general partner is Kagoshima Development Co., Ltd.) and by Grant-in-Aid for Young Scientists (B), JSPS KAKENHI (grant no. 18K16361).

\section{Availability of data and materials}

The datasets used and/or analyzed during the current study are available from the corresponding author on reasonable request.

\section{Authors' contributions}

HY and MM designed the study. HY, MM, YY and MU supervised the study. HT and YM are responsible for methodology. SS and SKou analyzed and interpreted of data and also confirmed the authenticity of all the raw data. JW, SB, YS, HH, KM and SuT performed the experiments. SKob and $\mathrm{HI}$ are responsible for statistical analysis. MU collected and provided the normal and colorectal cancer tissue samples and their clinical data. JW wrote the original draft. HY and MU reviewed and edited the manuscript. ShT and XW performed ODC degron-related experiments. All authors have read and approved the final manuscript.

\section{Ethics approval and consent to participate}

The present study was performed in accordance with the Declaration of Helsinki and all animal procedures (approval no. 13377-5) and patient-derived tissue experiments were approved by the Ethics Board of Osaka University (Osaka, Japan). All patients provided written informed consent, in accordance with the guidelines approved (approval no. 08226) by the Institutional Research Board of the institute.

\section{Patient consent for publication}

Not applicable. 


\section{Competing interests}

The authors declare that they have no competing interests.

\section{References}

1. Bray F, Ferlay J, Soerjomataram I, Siegel RL, Torre LA and Jemal A: Global cancer statistics 2018: GLOBOCAN estimates of incidence and mortality worldwide for 36 cancers in 185 countries. CA Cancer J Clin 68: 394-424, 2018.

2. Rawla P, Sunkara T and Barsouk A: Epidemiology of colorectal cancer: Incidence, mortality, survival, and risk factors. Prz Gastroenterol 14: 89-103, 2019.

3. Brenner H, Kloor M and Pox CP: Colorectal cancer. Lancet 383 . 1490-1502, 2014

4. Graham JS and Cassidy J: Adjuvant therapy in colon cancer. Expert Rev Anticancer Ther 12: 99-109, 2012.

5. Rupaimoole R and Slack FJ: MicroRNA therapeutics: Towards a new era for the management of cancer and other diseases. Nat Rev Drug Discov 16: 203-222, 2017.

6. Fischer SE: RNA Interference and MicroRNA-mediated silencing. Curr Protoc Mol Biol: Oct 1, 201 (Epub ahead of print). doi: 0.1002/0471142727.mb2601s112.

7. Mehta A and Baltimore D: MicroRNAs as regulatory elements in immune system logic. Nat Rev Immunol 16: 279-294, 2016.

8. Pons-Espinal M, de Luca E, Marzi MJ, Beckervordersandforth R, Armirotti A, Nicassio F, Fabel K, Kempermann G and De Pietri Tonelli D: Synergic functions of miRNAs determine neuronal fate of adult neural stem cells. Stem Cell Reports 8 : 1046-1061, 2017.

9. Aghaei M, Khodadadian A, Elham KN, Nazari M and Babakhanzadeh E: Major miRNA involved in insulin secretion and production in beta-cells. Int J Gen Med 13: 89-97, 2020.

10. Ali Syeda Z, Langden SSS, Munkhzul C, Lee M and Song SJ: Regulatory mechanism of MicroRNA expression in cancer. Int J Mol Sci 21: 1723, 2020.

11. Lee YS and Dutta A: MicroRNAs in cancer. Annu Rev Pathol 4: 199-227, 2009.

12. Li VS, Ng SS, Boersema PJ, Low TY, Karthaus WR, Gerlach JP, Mohammed S, Heck AJ, Maurice MM, Mahmoudi T and Clevers H: Wnt signaling through inhibition of $\beta$-catenin degradation in an intact Axin1 complex. Cell 149: 1245-1256, 2012.

13. Spano JP, Lagorce C, Atlan D, Milano G, Domont J, Benamouzig R, Attar A, Benichou J, Martin A, Morere JF, et al: Impact of EGFR expression on colorectal cancer patient prognosis and survival. Ann Oncol 16: 102-108, 2005.

14. Markowitz S, Wang J, Myeroff L, Parsons R, Sun L, Lutterbaugh J, Fan RS, Zborowska E, Kinzler KW, Vogelstein B, et al Inactivation of the type II TGF-beta receptor in colon cancer cells with microsatellite instability. Science 268: 1336-1338, 1995.

15. Baker SJ, Fearon ER, Nigro JM, Hamilton SR, Preisinger AC, Jessup JM, vanTuinen P, Ledbetter DH, Barker DF, Nakamura Y, et al: Chromosome 17 deletions and p53 gene mutations in colorectal carcinomas. Science 244: 217-221, 1989.

16. Thiery JP, Acloque H, Huang RY and Nieto MA: Epithelialmesenchymal transitions in development and disease. Cell 139: 871-890, 2009

17. Hiraki M, Nishimura J, Takahashi H, Wu X, Takahashi Y, Miyo M, Nishida N, Uemura M, Hata T, Takemasa I, et al Concurrent Targeting of KRAS and AKT by MiR-4689 is a novel treatment against mutant KRAS Colorectal cancer. Mol Ther Nucleic Acids 4: e231, 2015.

18. Inoue A, Mizushima T, Wu X, Okuzaki D, Kambara N, Ishikawa S, Wang J, Qian Y, Hirose H, Yokoyama Y, et al: miR-29b byproduct sequence exhibits potent tumour-suppressive activities via inhibition of $\mathrm{NF}-\kappa \mathrm{B}$ signaling in KRAS-mutant colon cancer cells. Mol Cancer Ther 17: 977-987, 2018.

19. Tazawa $H$, Tsuchiya $N$, Izumiya $M$ and Nakagama $H$ : Tumor-suppressive miR-34a induces senescence-like growth arrest through modulation of the E2F pathway in human colon cancer cells. Proc Natl Acad Sci USA 104: 15472-15477, 2007.

20. Morimoto Y, Mizushima T, Wu X, Okuzaki D, Yokoyama Y, Inoue A, Hata T, Hirose H, Qian Y, Wang J, et al: miR-4711-5p regulates cancer stemness and cell cycle progression via KLF5, MDM2 and TFDP1 in colon cancer cells. Br J Cancer 122: $1037-1049,2020$

21. Ayob AZ and Ramasamy TS: Cancer stem cells as key drivers of tumour progression. J Biomed Sci 25: 20, 2018.
22. Zhao J: Cancer stem cells and chemoresistance: The smartest survives the raid. Pharmacol Ther 160: 145-58, 2016.

23. de Sousa e Melo F, Kurtova AV, Harnoss JM, Kljavin N, Hoeck JD, Hung J, Anderson JE, Storm EE, Modrusan Z, Koeppen H, et al: A distinct role for $\mathrm{Lgr}^{+}$stem cells in primary and metastatic colon cancer. Nature 543: 676-680, 2017.

24. Vermeulen L, Todaro M, de Sousa Mello F, Sprick MR, Kemper K, Perez Alea M, Richel DJ, Stassi G and Medema JP: Single-cell cloning of colon cancer stem cells reveals a multi-lineage differentiation capacity. Proc Natl Acad Sci USA 105: 13427-1332, 2008.

25. Ren F, Sheng WQ and Du X: CD133: A cancer stem cells Marker, is used in colorectal cancers. World J Gastroenterol 19: 2603-2611, 2013.

26. Soheilifar MH, Moshtaghian A, Maadi H, Izadi F and Saidijam M: BMI1 roles in cancer stem cells and its association with MicroRNAs dysregulation in cancer: Emphasis on colorectal cancer. Int J Cancer Manag 11: 9, 2018.

27. Nakanishi Y, Seno H, Fukuoka A, Ueo T, Yamaga Y, Maruno T, Nakanishi N, Kanda K, Komekado H, Kawada M, et al: Dclk1 distinguishes between tumor and normal stem cells in the intestine. Nat Genet 45: 98-103, 2013.

28. Chandrakesan P, Weygant N, May R, Qu D, Chinthalapally HR, Sureban SM, Ali N, Lightfoot SA, Umar S and Houchen CW: DCLK1 facilitates intestinal tumor growth via enhancing pluripotency and epithelial mesenchymal transition. Oncotarget 5: 9269-9280, 2014.

29. Makino S, Takahashi H, Okuzaki D, Miyoshi N, Haraguchi N, Hata T, Matsuda C, Yamamoto H, Mizushima T, Mori M, et al: DCLK1 integrates induction of TRIB3, EMT, drug resistance and poor prognosis in colorectal cancer. Carcinogenesis 41: 303-312, 2020.

30. Westphalen CB, Takemoto Y, Tanaka T, Macchini M, Jiang Z, Renz BW, Chen X, Ormanns S, Nagar K, Tailor Y, et al: Dclk1 defines quiescent pancreatic progenitors that promote injury-induced regeneration and tumorigenesis. Cell Stem Cell 18: 441-455, 2016.

31. Weygant N, Qu D, May R, Tierney RM, Berry WL, Zhao L, Agarwal S, Chandrakesan P, Chinthalapally HR, Murphy NT, et al: DCLK1 is a broadly dysregulated target against epithelial-mesenchymal transition, focal adhesion, and stemness in clear cell renal carcinoma. Oncotarget 6: 2193-2205, 2015.

32. Adikrisna R, Tanaka S, Muramatsu S, Aihara A, Ban D, Ochiai T, Irie T, Kudo A, Nakamura N, Yamaoka S and Arii S: Identification of pancreatic cancer stem cells and selective toxicity of chemotherapeutic agents. Gastroenterology 143: 234-245.e7, 2012.

33. Munakata K, Uemura M, Tanaka S, Kawai K, Kitahara T, Miyo M, Kano Y, Nishikawa S, Fukusumi T, Takahashi Y, et al: Cancer stem-like properties in colorectal cancer cells with low proteasome activity. Clin Cancer Res 22: 5277-5286, 2016.

34. Qian Y, Wu X, Yokoyama Y, Okuzaki D, Taguchi M, Hirose H, Wang J, Hata T, Inoue A, Hiraki M, et al: E-cadherin-Fc chimera protein matrix enhances cancer stem-like properties and induces mesenchymal features in colon cancer cells. Cancer Sci 110: 3520-3532, 2019.

35. Pan YZ,Zhou A,Hu Z and Yu AM: Small nucleolar RNA-derived microRNA hsa-miR-1291 modulates cellular drug disposition through direct targeting of $\mathrm{ABC}$ transporter $\mathrm{ABCC} 1$. Drug Metab Dispos 41: 1744-1751, 2013.

36. Peng L, Chun-Guang Q, Bei-Fang L, Xue-Zhi D, Zi-Hao W, Yun-Fu L, Yan-Ping D, Yang-Gui L, Wei-Guo L, Tian-Yong $\mathrm{H}$ and Zhen-Wen H: Clinical impact of circulating miR-133, miR-1291 and miR-663b in plasma of patients with acute myocardial infarction. Diagn Pathol 9: 89, 2014.

37. Qiu L, Zhang L, Qi R, Gao X, Chen H and Xiao T: miR-1291 Functions as a potential serum biomarker for bullous pemphigoid. Dis Markers 2020: 9505312, 2020.

38. Chen Z, Wang X, Li L, Han M, Wang M, Li Z, Xie X, Du H, $\mathrm{Xie} Z$ and Zhang $\mathrm{H}$ : Construction of an autophagy interaction network based on competitive endogenous RNA reveals the key pathways and central genes of SARS-CoV-2 infection in vivo. Microb Pathog 158: 105051, 2021.

39. Hagag NA, Ali YB, Elsharawy AA and Talaat RM: Clinical impact of circulated miR-1291 in plasma of patients with liver cirrhosis (LC) and Hepatocellular Carcinoma (HCC): Implication on Glypican-3 Expression. J Gastrointest Cancer 51: 234-241, 2020.

40. Maurel M, Dejeans N, Taouji S, Chevet E and Grosset CF: MicroRNA-1291-mediated silencing of IRE1alpha enhances Glypican-3 expression. RNA 19: 778-788, 2013. 
41. Tu MJ, Duan Z, Liu Z, Zhang C, Bold RJ, Gonzalez FJ, Kim EJ and Yu AM: MicroRNA-1291-5p sensitizes pancreatic carcinoma cells to arginine deprivation and chemotherapy through the regulation of arginolysis and glycolysis. Mol Pharmacol 98: 686-694, 2020.

42. Tu MJ, Ho PY, Zhang QY, Jian C, Qiu JX, Kim EJ, Bold RJ, Gonzalez FJ, Bi H and Yu AM: Bioengineered miRNA-1291 prodrug therapy in pancreatic cancer cells and patient-derived xenograft mouse models. Cancer Lett 442: 82-90, 2019.

43. Tu MJ, Pan YZ, Qiu JX, Kim EJ and Yu AM: MicroRNA-1291 targets the FOXA2-AGR2 pathway to suppress pancreatic cancer cell proliferation and tumorigenesis. Oncotarget 7: 45547-45561, 2016.

44. Yamasaki T, Seki N, Yoshino H, Itesako T, Yamada Y, Tatarano S, Hidaka H, Yonezawa T, Nakagawa M and Enokida $\mathrm{H}$ : Tumor-suppressive microRNA-1291 directly regulates glucose transporter 1 in renal cell carcinoma. Cancer Sci 104: 1411-149, 2013.

45. Luo H, Guo W, Wang F, You Y, Wang J, Chen X, Wang J, Wang Y, Du Y, Chen X, et al: miR-1291 targets mucin 1 inhibiting cell proliferation and invasion to promote cell apoptosis in esophageal squamous cell carcinoma. Oncol Rep 34: 2665-2673, 2015.

46. Cai Q, Zhao A, Ren L, Chen J, Liao K, Wang Z and Zhang W: MicroRNA-1291 mediates cell proliferation and tumorigenesis by downregulating MED1 in prostate cancer. Oncol Lett 17: 3253-3260, 2019

47. Salehi Z, Hadadi P and Tavallaei O: Prediction of biomarker miRNAs signature in colorectal cancer metastasis to liver cancer. Electron J Gen Med 16: em100, 2019.

48. Morikawa K, Walker SM, Nakajima M, Pathak S, Jessup JM and Fidler IJ: Influence of organ environment on the growth, selection, and metastasis of human colon carcinoma cells in nude mice. Cancer Res 48: 6863-6871, 1988.

49. Livak KJ and Schmittgen TD: Analysis of relative gene expression data using real-time quantitative PCR and the 2(-Delta Delta C(T)) method. Methods 25: 402-408, 2001

50. Jin H, Li XJ, Park MH and Kim SM: FOXM1-mediated downregulation of uPA and MMP9 by 3,3'-diindolylmethane inhibits migration and invasion of human colorectal cancer cells. Oncol Rep 33: 3171-3177, 2015.

51. Jung H, Kim HS, Lee JH, Lee JJ and Park HS: Wound healing promoting activity of tonsil-derived stem cells on 5-Fluorouracil-Induced oral mucositis model. Tissue Eng Regen Med 17: 105-119, 2020

52. Wu X, Yamamoto H, Nakanishi H, Yamamoto Y, Inoue A, Tei M, Hirose H, Uemura M, Nishimura J, Hata T, et al: Innovative delivery of siRNA to solid tumors by super carbonate apatite. PLoS One 10: e0116022, 2015.

53. Ogawa H, Wu X, Kawamoto K, Nishida N, Konno M, Koseki J, Matsui H, Noguchi K, Gotoh N, Yamamoto T, et al: MicroRNAs induce epigenetic reprogramming and suppress malignant phenotypes of human colon cancer cells. PLoS One 10: e0127119, 2015

54. Takeyama H, Yamamoto $H$, Yamashita $S$, Wu X, Takahashi $H$, Nishimura J, Haraguchi N, Miyake Y, Suzuki R, Murata K, et al: Decreased miR-340 expression in bone marrow is associated with liver metastasis of colorectal cancer. Mol Cancer Ther 13: 976-985, 2014

55. Fukata T, Mizushima T, Nishimura J, Okuzaki D, Wu X, Hirose H, Yokoyama Y, Kubota Y, Nagata K, Tsujimura N, et al: The Supercarbonate Apatite-MicroRNA complex inhibits dextran sodium sulfate-induced colitis. Mol Ther Nucleic Acids 12: 658-671, 2018.

56. SCJ (Science Council of Japan): Guidelines for Proper Conduct of Animal Experiments, 2006.

57. UCI Office of Research: Euthanasia of Research Animals. Assessment Criteria for Confirmation of Death, 2014.

58. Mogavero A, Maiorana MV, Zanutto S, Varinelli L, Bozzi F, Belfiore A, Volpi CC, Gloghini A, Pierotti MA and Gariboldi M: Metformin transiently inhibits colorectal cancer cell proliferation as a result of either AMPK activation or increased ROS production. Sci Rep 7: 15992, 2017.

59. Gharib E, Nasri Nasrabadi P and Reza Zali M: miR-497-5p mediates starvation-induced death in colon cancer cells by targeting acyl-CoA synthetase-5 and modulation of lipid metabolism J Cell Physiol 235: 5570-5589, 2020.

60. Zou P, Zhu M, Lian C, Wang J, Chen Z, Zhang X, Yang Y, Chen X, Cui X and Liu J: miR-192-5p suppresses the progression of lung cancer bone metastasis by targeting TRIM44. Sci Rep 9: 19619, 2019.

61. Weng J, Zhang H, Wang C, Liang J, Chen G, Li W, Tang H and Hou J: miR-373-3p targets DKK1 to promote EMT-Induced metastasis via the $\mathrm{Wnt} / \beta$-Catenin pathway in tongue squamous cell carcinoma. Biomed Res Int 2017: 6010926, 2017.
62. Forterre A, Komuro H, Aminova S and Harada M: A Comprehensive review of cancer MicroRNA therapeutic delivery strategies. Cancers (Basel) 12: 1852, 2020.

63. Abd-Aziz N, Kamaruzman NI and Poh CL: Development of MicroR NAs as Potential Therapeutics against Cancer. J Oncol 2020: 8029721, 2020.

64. Merhautova J, Demlova R and Slaby O: MicroRNA-Based therapy in animal models of selected gastrointestinal cancers. Front Pharmacol 7: 329, 2016

65. Takahashi RU, Prieto-Vila M, Kohama I and Ochiya T: Development of miRNA-based therapeutic approaches for cancer patients. Cancer Sci 110: 1140-1147, 2019.

66. Sadanandam A, Lyssiotis CA, Homicsko K, Collisson EA, Gibb WJ, Wullschleger S, Ostos LC, Lannon WA, Grotzinger C, Del Rio M, et al: A colorectal cancer classification system that associates cellular phenotype and responses to therapy. Nat Med 19: 619-625 2013.

67. Yeung TM, Gandhi SC, Wilding JL, Muschel R and Bodmer WF: Cancer stem cells from colorectal cancer-derived cell lines. Proc Natl Acad Sci USA 107: 3722-3727, 2010.

68. Chen KL, Pan F, Jiang H, Chen JF, Pei L, Xie FW and Liang HJ: Highly enriched CD133(+)CD44(+) stem-like cells with CD133(+) CD44(high) metastatic subset in HCT116 colon cancer cells. Clin Exp Metastasis 28: 751-763, 2011.

69. DexterDL,Barbosa JAandCalabresi P: N,N-dimethylformamideinduced alteration of cell culture characteristics and loss of tumorigenicity in cultured human colon carcinoma cells. Cancer Res 39: 1020-1025, 1979.

70. Miyamoto M, Sawada K, Nakamura K, Yoshimura A, Ishida K, Kobayashi M, Shimizu A, Yamamoto M, Kodama M, Hashimoto K and Kimura T: Paclitaxel exposure downregulates miR-522 expression and its downregulation induces paclitaxel resistance in ovarian cancer cells. Sci Rep 10: 16755, 2020.

71. Seki Y, Yamamoto H, Ngan CY, Yasui M, Tomita N, Kitani K, Takemasa I,Ikeda M, Sekimoto M, Matsuura N, et al: Construction of a novel DNA decoy that inhibits the oncogenic beta-catenin/ T-cell factor pathway. Mol Cancer Ther 5: 985-994, 2006.

72. O'Connell MR, Sarkar S, Luthra GK, Okugawa Y, Toiyama Y, Gajjar AH, Qiu S, Goel A and Singh P: Epigenetic changes and alternate promoter usage by human colon cancers for expressing DCLK1-isoforms: Clinical implications. Sci Rep 5: 14983, 2015.

73. Sarkar S, O'Connell MR, Okugawa Y, Lee BS, Toiyama Y, Kusunoki M, Daboval RD, Goel A and Singh P: FOXD3 Regulates CSC Marker, DCLK1-S, and invasive potential: Prognostic implications in colon cancer. Mol Cancer Res 15: 1678-1691, 2017

74. Manhas J, Bhattacharya A, Agrawal SK, Gupta B, Das P, Deo SV, Pal S and Sen S: Characterization of cancer stem cells from different grades of human colorectal cancer. Tumour Biol 37: 14069-140812016.

75. Kantara C, O'Connell M, Sarkar S, Moya S, Ullrich R and Singh P: Curcumin promotes autophagic survival of a subset of colon cancer stem cells, which are ablated by DCLK1-siRNA. Cancer Res 74: 2487-2498, 2014.

76. Ji D, Zhan T, Li M, Yao Y, Jia J, Yi H, Qiao M, Xia J, Zhang Z, Ding $\mathrm{H}$, et al: Enhancement of sensitivity to Chemo/Radiation therapy by using miR-15b against DCLK1 in colorectal cancer. Stem Cell Reports 11: 1506-1522, 2018.

77. Abukhdeir AM and Park BH: P21 and p27: Roles in carcinogenesis and drug resistance. Expert Rev Mol Med 10: e19, 2008.

78. Slingerland J and Pagano M: Regulation of the Cdk Inhibitor p27 and Its Deregulation in Cancer J Cell Physiol 183: 10-17, 2000.

79. LaBaer J, Garrett MD, Stevenson LF, Slingerland JM, Sandhu C, Chou HS, Fattaey A and Harlow E: New functional activities for the p21 family of CDK inhibitors. Genes Dev 11: 847-862, 1997.

80. Wang Y, Ji P, Liu J, Broaddus RR, Xue F and Zhang W: Centrosome-associated regulators of the $\mathrm{G}(2) / \mathrm{M}$ checkpoint as targets for cancer therapy. Mol Cancer 8: 8, 2009.

81. To KK, Tong CW, Wu M and Cho WC: MicroRNAs in the prognosis and therapy of colorectal cancer: From bench to bedside. World J Gastroenterol 24: 2949-2973, 2018.

82. Chi Y and Zhou D: MicroRNAs in colorectal carcinoma-from pathogenesis to therapy. J Exp Clin Cancer Res 35: 43, 2016.

This work is licensed under a Creative Commons Attribution-NonCommercial-NoDerivatives 4.0 International (CC BY-NC-ND 4.0) License. 